Board of Governors of the Federal Reserve System

International Finance Discussion Papers

Number 1115

August 2014

Employment and Firm Heterogeneity, Capital Allocation, and Countercyclical Labor Market Policies

Brendan Epstein

Alan Finkelstein Shapiro

NOTE: International Finance and Discussion Papers are preliminary materials circulated to stimulate discussion and critical comment. References in publications to International Finance Discussion Papers (other than an acknowledgment that the writer has had access to unpublished material) should be cleared with the author or authors. Recent IDFPs are available on the Web at www.federalreserve.gov/pubs/ifdp/. This paper can be downloaded without charge from Social Science Research Network electronic library at www.ssrn.com. 


\title{
Employment and Firm Heterogeneity, Capital Allocation, and Countercyclical Labor Market Policies*
}

\author{
Brendan Epstein ${ }^{\dagger}$ \\ Federal Reserve Board \\ Alan Finkelstein Shapiro \\ Universidad de Los Andes
}

August 23, 2014

\begin{abstract}
Many countries have large employment shares in micro and small firms that have limited access to formal financing and therefore rely on input credit. Such countries are mainly emerging and developing economies, whose business cycle dynamics are increasingly important for the global economy in light of the dramatic rise in international linkages and spillovers that have occurred over the last several decades. Emerging and developing economies implemented a host of countercyclical labor market policies amid the global financial crisis, but data limitations on high-frequency labor and job flows prevent a detailed empirical assessment of the effectiveness of these policies. To address this problem, we develop a business cycle model with frictional labor markets that is novel in light of its consistency with the employment and firm structure of emerging and developing economies. We use the model to assess the aggregate impact of key countercyclical labor market policies. We find that hiring subsidies and job intermediation services for large firms are particularly effective in aiding recoveries. Policies targeting smaller firms yield limited aggregate benefits and may even be detrimental to the recovery process. The labor market structure shapes sectoral allocation and explains the economy's differential response to policy.
\end{abstract}

JEL Classifications: E24, E32, J64

Keywords: business cycles, search frictions, fiscal policy, self employment, small firms, input credit.

${ }^{*}$ This paper was previously circulated as "Firm and Job Creation Policies During Recessions in Emerging Economies." The views in this paper are solely the responsibility of the authors and should not be interpreted as representing the views of the Board of Governors of the Federal Reserve System or of any other person associated with the Federal Reserve System. The authors thank, without implicating, William Maloney, Mariano Bosch, Julián Messina, Andrés González Gómez, and seminar participants in the 2014 LACEA Labor Network for valuable comments and feedback. The authors are also grateful for useful discussions during visits to Brown University, the Federal Reserve Bank of Atlanta, the Federal Reserve Bank of Philadelphia, and the Federal Reserve Bank of Richmond. Any errors are the authors' own.

${ }^{\dagger}$ E-mail: brendan.epstein@frb.gov. Phone: 202-721-4593. Correspondence: Board of Governors of the Federal Reserve System; 20th St. and Constitution Ave. NW; Washington, D.C. 20551.

${ }_{\ddagger}^{\ddagger}$ E-mail: alanfshapiro@gmail.com. Phone: (571) 313-805-9115. Correspondence: Calle 19A No. 1-37 Este, Bloque W; Department of Economics, Universidad de los Andes; Bogotá, Colombia. 


\section{Introduction}

Many countries have large employment shares in micro firms (also referred to as own-account or self-employment firms, that is, one-worker firms) and small (salaried) firms. These firms, compared to large firms, are less capital-intensive, often have limited access to formal financing, and rely on interfirm input credit and other informal sources to meet their non-labor input needs (Global Financial Development Report, 2014). Countries with this employment and firm structure are mainly emerging and developing economies, which increasingly generate a nontrivial fraction of world output. Emerging and developing economies implemented a host of countercyclical labor market policies amid the global financial crisis (Table 1). Some of the most prominent policies included temporary wage and hiring subsidies, the temporary expansion of job intermediation services, and the expansion of public expenditures to support the creation of micro and small firms via credit facilities, among others (Table 2).

Limitations on the frequency and availability of detailed data on labor and job flows for most emerging economies pose a serious challenge for in-depth empirical assessments of the benefits, costs, and aggregate effects of these policies on employment and economic activity. As these economies continue to improve their ability to implement countercyclical policy, it is increasingly important to understand the impact of different policy tools in response to adverse shocks, and especially so given the dramatic rise in international linkages and spillovers that have occurred over the last several decades. Yet, extrapolating conclusions from similar labor market policies implemented in advanced economies is ultimately inadequate given several distinctive characteristics of emerging economies' labor market and firm structure.

Table 1:

Percent of Low- and Middle-Income Countries that Implemented Labor Demand and Job Matching Policies

\begin{tabular}{cc}
\hline \hline Type of Policy & Percent of Countries \\
\hline Direct Job Creation and Employment Incentives & 80 \\
Credit Facilities, Access to Credit & 65 \\
Lower Non-Wage Labor Costs, Other Taxes & 58 \\
Public Employment Services & 53 \\
Special Measures for Small and Medium Enterprises & 49 \\
Subsidies for Job Creation & 44 \\
\hline
\end{tabular}

Source: Figures 10 and 14, ILO and World Bank (2012). Notes: The sample of low- and middle-income economies includes 55 countries. 58 percent of the country sample introduced training for the unemployed. 
Table 2:

Allocation of Expenditures, Labor Demand and Job Matching Policies: Low- and Middle-Income Countries

\begin{tabular}{cc}
\hline \hline & Budget Allocation within \\
Labor Demand Policies & Policy Category (Percent ) \\
\hline Direct Job Creation and Employment Incentives & 66.95 \\
Subsidies to Employers Maintaining Existing Jobs & 14.54 \\
Credit Facilities, Access to Credit & 12.97 \\
Special Measures for Small and Medium Enterprises & 3.04 \\
\hline & Budget Allocation within \\
Programs that Improve Job Matching Skills & Policy Category (Percent) \\
\hline Public Employment Services & 43 \\
Training for Unemployed & 31 \\
Training for Employed & 20 \\
\hline
\end{tabular}

Source: Figures 11 and 15, ILO and World Bank (2012). Notes: The sample of low- and middle-income economies includes 55 countries. Subsidies to employers maintaining jobs include wage subsidies.

To get around these limitations, we develop a tractable and novel business cycle model with frictional labor markets and firm heterogeneity. The model is consistent with the employment and firm structure of emerging and developing economies. In particular, we exploit the increasingly rich evidence on the employment and firm structure of several Latin American economies to guide our modeling choices. Then, we use the model as a tractable laboratory to study the aggregate consequences and effectiveness of several cyclical labor-demand and firm-creation policies that were implemented by emerging and developing economies during the global financial crisis.

The structure of the model is based on the following facts. First, relative to advanced economies, the share of self-employment in Latin American economies is substantial, ranging anywhere from 20 to 40 percent of total employment and reaching even higher rates in many developing economies (Perry et al., 2007; Loayza and Rigolini, 2011). Second, a larger fraction of firms in these economies are micro or small, and they employ a larger share of salaried employment relative to advanced economies (Table 3; Global Financial Development Report, 2014).

Third, while bank credit and other formal financing sources are more often available for larger firms in emerging and developing economies, micro and small firms tend to be informal and face severe difficulties in obtaining formal external financing. In fact, micro and small firms often cite access to finance as their biggest obstacle (Kantis, Ishida, and Komori, 2002; IDB, 2005a, 2005b; Global Financial Development Report, 2014). As a consequence of the 
lack of formal external financing, many of these firms exhibit a smaller scale, must search for suppliers and customers to obtain input credit, and hence must rely on alternative, informal financing sources generally based on relationship lending (Tables 4 and 5; Farazi, 2014).

Table 3:

Size Distribution of Salaried Employment and Establishment for Select Countries

\begin{tabular}{ccccccccc}
\hline \hline Firm & \multicolumn{3}{c}{ U.S. } & \multicolumn{2}{c}{ Mexico } & \multicolumn{2}{c}{ Argentina } & \multicolumn{2}{c}{ Bolivia } \\
Size & Empl. & Estab. & Empl. & Estab. & Empl. & Estab. & Empl. & Estab. \\
\hline $1-9$ & 4.2 & 54.5 & 22.7 & 90.5 & 22 & 84.0 & 43.6 & 91.7 \\
$10-19$ & 4.8 & 14.5 & 5.5 & 4.2 & 25 & 12.9 & 10.0 & 4.2 \\
$20-49$ & 11 & 14.7 & 8 & 2.7 & 19 & 2.5 & 13.6 & 2.6 \\
$50-99$ & 12.3 & 7.4 & 7.5 & 1.1 & 35 & 0.8 & 9.8 & 0.8 \\
$100+$ & 67.7 & 8.9 & 56.3 & 1.6 & 18 & 0.2 & 23.0 & 0.6 \\
\hline
\end{tabular}

Source: Taken directly from Busso, Madrigal, and Pagés (2012).

Notes: Empl. and Estab. stand for Employment and Establishments, respectively. The sample year varies by country. The data in the table is for manufacturing firms only, although similar patters hold for other sectors. The evidence in the table provides a lower bound for the share of small firms, small-firm salaried employment, and self-employment since the Mexican census only considers firms with a fixed location and hence excludes a non-negligible share of employment and firms in the economy.

Table 4:

Consequences of Lack of External Financing for Latin American Small Firms

\begin{tabular}{cc}
\hline \hline Consequence of Restricted Access to Financing & Percent of Entrepreneurs \\
\hline Reduced Scale & 56.0 \\
Search for Partners & 11.0 \\
Search for Support from Suppliers or Customers & 51.0 \\
Delay in Launching Enterprise & 32.0 \\
\hline
\end{tabular}

Source: Taken directly from Table 6.5, IDB (2005b).

Table 5:

Percent of Small Entrepreneurs Using Alternative Financing Sources: Latin America

\begin{tabular}{ccc}
\hline \hline Financing Sources & Startup & Early Years \\
\hline Suppliers & 32.0 & 36.6 \\
Purchase of Second-Hand Machinery and Equipment & 27.5 & 20.6 \\
Customers & 18.0 & 19.1 \\
Delaying Payment of Services & 8 & 3.5 \\
\hline
\end{tabular}

Source: Taken directly from Table 6.2, IDB (2005b).

Importantly, Table 5 shows that as small firms grow older their reliance on alternative financing sources, such as credit from suppliers, customers, and the purchase of used machinery 
and equipment - all being relationship-based sources of input credit-remains important. ${ }^{1}$ These are key differences relative to advanced economies where small firms, while also constrained relative to larger firms, usually have better access to formal financing. Finally, as a simple example, Table 6 shows the allocation of resources by firm size in Mexico. This evidence - which is similar for other economies in the region-suggests that a very small share of total capital is allocated among micro and small salaried firms.

Table 6:

Allocation of Resources by Firm Size in Mexico

\begin{tabular}{cccc}
\hline \hline Firm Size & Capital & Workers & Value Added \\
\hline $0-5$ & 13.2 & 37.8 & 10.3 \\
$6-10$ & 4.5 & 8.8 & 4.6 \\
$11-50$ & 10.2 & 14.9 & 12.5 \\
$50+$ & 72.1 & 38.5 & 72.5 \\
\hline
\end{tabular}

Source: Busso, Fazio, and Levy (2012). Notes: The evidence in the table provides a lower bound for the share of small firms, small-firm salaried employment, and self-employment since the Mexican census only considers firms with a fixed location and hence excludes a non-negligible share of employment and firms in the economy.

Based on the above facts, our model differentiates between self-employed (or micro) firms, small salaried firms, and large firms based on capital intensity, productivity, and the reliance of input credit by micro and small firms in a tractable way. Following Finkelstein Shapiro (2014), large salaried firms act as input credit suppliers to self-employed firms through frictional capital markets. We expand this framework on two fronts. First, owner-only (selfemployed, or micro) firms can choose to expand to become small salaried firms. The notion of size in the model is related to a restriction on variable capital usage by small salaried firms and their continued reliance on external financing from larger firms via capital relationships, as in the data. Second, small firms can hire additional workers. Thus, the model incorporates both endogenous small firm creation and expansion. Overall, this structure is consistent with the small allocation of capital among small firms in developing economies (Busso, Fazio, and Levy, 2012), and establishes an important link between large firms, self-employed, and small firms through input credit markets. ${ }^{2}$ We show that the model successfully captures the

\footnotetext{
${ }^{1}$ While firms in East Asia tend to rely less on these financing sources as they age, input credit remains a relevant source of financing (IDB, 2005b).

${ }^{2}$ In order to clearly focus on labor-market issues, we assume the context of a closed economy. However, as discussed in the Appendix, assuming instead a small open-economy context does not change our main results.
} 
cyclical dynamics of salaried employment, self-employment, and their respective flows from unemployment in the data.

We consider the aggregate consequences of introducing cyclical hiring subsidies for large and small salaried firms, hiring subsidies for self-employed firms (which foster the creation of small salaried firms), subsidies for the creation of self-employed firms, and wage subsidies. We also consider policies that improve the matching process between salaried firms and the unemployed during downturns, where these policies are meant to capture the expansion of government-provided job intermediation services during recessions. All these policies were important policy tools during the global financial crisis (Tables 1 and 2; ILO and World Bank, 2012).

Our analysis focuses on individual cyclical policies that generate the same fiscal cost at the onset of a downturn. Results show that the type of firm targeted by the policy (owner-only or micro, small, or large) matters for the effectiveness of cyclical labor market interventions in aiding employment and output recoveries. In particular, the reallocation of capital across firms (and hence the functioning of interfirm input credit markets and their interaction with the labor market) along with the effect that this reallocation has on relative employment by small and large firms plays an important role in the effectiveness of policy. Certain policies can generate tradeoffs between limiting the rise in unemployment as the recession hits and aiding the recovery in the medium term. Other policies not only yield gains along both of those margins but also provide better income protection.

In particular, our results imply that, while policies that focus on small firms can successfully protect employment, these policies have limited effects on the output recovery path. In contrast, policies that improve intermediation between the unemployed and larger firms yield gains across the board. Moreover, policies that foster the creation of microfirms can be detrimental to the recovery process and yield negligible benefits in terms of employment and income protection. Model-implied fiscal multipliers suggest that hiring subsidies and job intermediation for large firms are particularly effective in aiding recoveries. These results are important in light of the fact that, amid the global financial crisis, many emerging economies introduced particular policies targeting micro and small and medium enterprises (SMEs).

Our work is related to the growing literature on business cycles and search frictions, as 
well as the literature on the impact of fiscal policy in the context of the recent crisis. Most related to our paper is the work by Nicoletti and Pierrard (2006) who develop a model where small salaried firms must first match with a financial intermediary to obtain capital and then search for a single worker to produce. Our model differs from that of Nicoletti and Pierrard in three key aspects. First, while small firms in our framework are also created endogenously, they can employ multiple workers and, once established, can also expand by hiring additional workers. Second, we introduce self-employed firms - a key characteristic of emerging-economy labor markets - which can endogenously expand and become small salaried firms. Finally, we use capital search in such a way that, in line with the data, selfemployment is countercyclical, small firm owners (and therefore small firms) are procyclical, and both self-employed and small firms rely on input credit relationships. ${ }^{3}$

Less directly related to our work, but among research exploring the effects of labor market policies during the global financial crisis, are studies that focus on advanced economies. Kitao, Şahin, and Song (2010) study the impact of job creation policies introduced in the U.S. using a partial-equilibrium search and matching model. Campolmi, Faia, and Winkler (2011) analyze the impact of fiscal policy and hiring subsidies on employment in a general equilibrium setting with labor search frictions and show that hiring subsidies can yield large fiscal multipliers. Also, Totzek and Winkler (2010) explore the role of fiscal policy in an environment with endogenous firm entry, but abstract from studying labor market dynamics. ${ }^{4}$ Finally, Lee and Mukoyama (2013) build a model of industry dynamics that captures the cyclical properties of entry and exit in the U.S. manufacturing sector to analyze the role of entry subsidies during recessions, but they abstract from labor market frictions.

We contribute on three main fronts to: the existing literature on firm and labor market dynamics over the business cycle in emerging economies; and to recent studies on the impact of cyclical labor market policies during recessions. First, our model accounts for the large shares of self-employment in developing countries in a way that is consistent with the cyclical dynamics of self-employment and salaried employment in the data, and does so in

\footnotetext{
${ }^{3}$ As shown in Finkelstein Shapiro (2014), the capital search structure we use is important to capture the cyclical dynamics of self-employment and entry into self-employment in developing countries.

${ }^{4}$ For related work on firm entry and business cycles, see Shao and Silos (2008). For studies that merge labor market and firm dynamics in a business cycle context, see Sedláček (2011), Sedláček and Sterk (2013) and Siemer (2013), among others.
} 
a tractable environment with firm heterogeneity based on capital intensity and access to external finance among small firms. Existing models of firm entry over the business cycle generally abstract from the fact that many new firms, particularly in emerging economies, start off as being one-person firms that either remain without workers or slowly expand via salaried employment creation. Our framework tractably accommodates this feature. Second, to the best of our knowledge, we are the first to analyze the aggregate impact of cyclical labor market policies in developing countries within the context of a business cycle model consistent with the employment and firm structure of these economies. Third, with regards to the policies we consider, a key difference relative to the existing business cycle literature is that we analyze interventions that explicitly support the creation and expansion of self-employment ventures and small firms during downturns. These interventions have been common in several emerging economies and are particularly relevant in economies with both large self-employment shares and large employment shares among small firms. Importantly, we characterize the effectiveness of policies that specifically target these firms.

The remainder of this paper is organized as follows. Section 2 develops the model. Section 3 describes the model's calibration. Section 4 presents the main results from our policy experiments and discusses the fiscal implications of different policies. Finally, Section 5 concludes.

\section{The Model}

The economy is inhabited by an infinitely-lived representative household with a large number of members whose population consists of a unit mass. All household members participate in the labor force. Following related literature, there is perfect risk-pooling across household members. Final output, whose price is normalized to 1, is produced using as intermediate inputs the production of large firms, small firms, and owner-only firms. The product market is perfectly competitive. ${ }^{5}$ However, labor-market frictions are such that the wages for salaried workers in both large and small firms, as well as the capital rental rates for self-employed and

\footnotetext{
${ }^{5}$ Also, while the model accounts for firm and employment heterogeneity, for simplicity we focus on homogeneous workers. See Epstein (2012) and Arseneau and Epstein (2014), among others, for research on the aggregate implications of both firm and worker heterogeneity.
} 
small business owners, are negotiated via Nash bargaining. Taken together, our assumptions on large and small firms yield a larger concentration of capital in the large-firm sector, which is consistent with the evidence in Busso, Fazio, and Levy (2012) and others.

Large firms are capital intensive (compared to small firms), undertake capital accumulation internally, and make capital allocation decisions - that is, they choose the share of capital used in their own production and consequently the share of capital available as input credit for self-employed individuals and small firms. This capital is supplied through frictional capital markets. Large firms also hire salaried workers in frictional labor markets.

Self-employed (or own-account) individuals operate owner-only firms. These firms produce using a single unit of capital and a fixed (normalized) unit of self-employment labor. Importantly, these firms cannot accumulate capital internally. As in Finkelstein Shapiro (2014), obtaining capital to enter self-employment is subject to search frictions so that production capital is obtained by establishing an input credit relationship with large firms (capital suppliers). Owner-only firms also post vacancies and therefore can become small salaried firms by hiring employees through frictional labor markets. If at least one of these vacancies is successfully filled, a self-employed individual becomes a small salaried firm owner.

Small firms cannot accumulate capital internally, they are less capital intensive than large firms, and they continue to rely on a capital relationship with large firms to be operational (after having made the transition from micro firm to small salaried firm). For aggregation purposes (discussed below) we assume that each small firm also needs one, and only one, unit of capital to be operational. Thus, each small salaried firm uses a unit of capital and salaried workers to produce. These salaried workers are hired through frictional labor markets.

\subsection{Self-Employment, Small Firms, and Households}

\subsubsection{Self-Employment}

Total profits from self-employed individuals are:

$$
\Pi_{S E, t}=\left(p_{S E, t} z_{S E, t}-r_{S E, t}-\tau_{t}^{v_{S E}} \psi_{S E} v_{S E, t}\right) n_{S E, t},
$$


where: $p_{S E, t}$ is the price of self-employment output; $z_{S E, t}$ is self-employment productivity;

$r_{S E, t}$ is the endogenous Nash rental rate of capital paid by small businesses; $\tau_{t}^{v_{S E}}$ is a policy that equals 1 in steady state and decreases (increases) when output is below (above) trend (thus, it acts as a hiring subsidy during downturns); $\psi_{S E}$ is the fixed, exogenous flow cost of posting vacancies; $v_{S E, t}$ is the number of vacancies posted by each self-employed individual in order to expand and become a small firm owner; and $n_{S E, t}$ is the mass of self-employed individuals. Total output from self-employment is given by $y_{S E, t}=z_{S E, t} n_{S E, t}$.

\subsubsection{Small Salaried Firms}

Total profits from small firms are given by

$$
\begin{gathered}
\Pi_{S B, t}=\left[p_{S B, t} z_{S B, t} F\left(\frac{n_{S B, t}}{o_{S B, t}}, 1\right)-\tau_{t}^{w_{S B}} w_{S B, t} \frac{n_{S B, t}}{o_{S B, t}}\right] o_{S B, t} \\
-r_{S B, t} o_{S B, t}-\tau_{t}^{v_{S B}} \psi_{S B} v_{S B, t} o_{S B, t}
\end{gathered}
$$

where: $p_{S B, t}$ is the price of output in the small firm sector; $z_{S B, t}$ is the exogenous productivity of small firms; the production function of an individual small firm, $F(\cdot, \cdot)$, is increasing and concave in each of its arguments (the first argument is salaried labor used per small firm and the second argument is capital usage per small firm - we assume that all operating small firms are identical, which, as shown below, leads to straightforward sectoral aggregation); $n_{S B, t}$ is the total mass of individuals employed by small firms; $w_{S B, t}$ is the wage paid to small-firm employees; $o_{S B, t}$ is the total mass of small firm owners; $r_{S B, t}$ is the endogenous rental rate of capital paid by small firms; $\psi_{S B}$ is a fixed and exogenous flow cost of posting vacancies; $v_{S B, t}$ is the number of vacancies posted by each small firm; and $\tau_{t}^{v_{S B}}$ and $\tau_{t}^{w_{S B}}$ are time-varying policies (hiring and wage subsidies, respectively) that equal 1 in steady state and decrease (increase) when total output is below (above) trend.

Given our assumptions on the production function of individual small firms, equation (2) 
can be restated as:

$$
\begin{aligned}
\Pi_{S B, t}= & p_{S B, t} z_{S B, t} F\left(n_{S B, t}, o_{S B, t}\right)-\tau_{t}^{w_{S B}} w_{S B, t} n_{S B, t} \\
& -r_{S B, t} O_{S B, t}-\tau_{t}^{v_{S B}} \psi_{S B} v_{S B, t} o_{S B, t}
\end{aligned}
$$

It follows that, from a sectoral perspective, total output from small businesses is increasing and concave in small firm employees and small firm capital. Note that because each individual production entity uses one and only one unit of capital, $o_{S B}$ represents both the mass of small business owners and the total mass of capital rented by small firms. Total output from small firms is given by $y_{S B, t}=z_{S B, t} F\left(n_{S B, t}, o_{S B, t}\right)$.

\subsubsection{Employment-State Evolution}

All job finding and filling probabilities, discussed further below, depend on market tightness and are therefore endogenous. Job destruction probabilities, also discussed further below, are assumed to increase (decrease) when total output is below (above) trend. This assumption is broadly in line with the introduction of countercyclical job-destruction probabilities in Shimer (2005). We make these assumptions on job destruction in order to keep the model tractable while still being able to get at the issue of how labor market policies may affect the pace of recoveries and hence of job destruction itself.

An unemployed job seeker finds a job in a large firm with probability $f_{L, t}$ and these jobs are destroyed with probability $\rho_{t}^{L}$. Therefore, from the household's labor supply perspective the mass of individuals employed by large firms $n_{L, t}$ evolves in the following way:

$$
n_{L, t+1}=\left(1-\rho_{t}^{L}\right)\left(n_{L, t}+f_{L, t} u_{t}\right),
$$

where $u_{t}$ is the mass of unemployed individuals.

For a self-employment opportunity to arise the household must form a match with a capital supplier. In order to form such matches, the household spends resources $s_{K, t}$ on capital search. Matches with capital suppliers are formed with probability $f_{K, t}$. Once a match with a capital supplier is formed, an unemployed individual is assigned to self-employment 
status. As noted earlier, self-employed individuals post vacancies $v_{S E, t}$, which allows them to expand and become small firm owners by hiring workers.

Transitioning from being a self-employed individual into a small firm owner occurs with endogenous probability $q_{S E, t}$. Both existing and newly formed matches with capital suppliers are destroyed with probability $\rho_{t}^{K}$. In addition, a small firm is destroyed with probability $\rho_{t}^{O}$, but in that instance the former small firm owner retains the capital supplier relationship and transitions back to self-employment. Finally, the probability that a salaried position is destroyed in a surviving small firm is $\rho_{t}^{S}$.

It follows that, from the household's perspective, the mass of self-employed individuals $n_{S E, t}$ satisfies:

$$
n_{S E, t+1}=\left(1-\rho_{t}^{K}\right)\left\{\left[1-\left(1-\rho_{t}^{O}\right)\left(1-\rho_{t}^{S}\right) v_{S E, t} q_{S E, t}\right] n_{S E, t}+\rho_{t}^{O} O_{S B, t}+s_{K, t} f_{K, t}\right\}
$$

and the mass of small firm owners evolves as follows:

$$
o_{S B, t+1}=\left(1-\rho_{t}^{K}\right)\left(1-\rho_{t}^{O}\right)\left[o_{S B, t}+\left(1-\rho_{t}^{S}\right) v_{S E, t} q_{S E, t} n_{S E, t}\right]
$$

From a labor demand perspective, at the start of a period $n_{S B, t}^{d}$ individuals are employed by small firms. Self-employed individuals seeking to become small firms post a total of $v_{S E, t} n_{S E, t}$ vacancies and existing small firms post a total of $v_{S B, t} O_{S B, t}$ vacancies. Therefore,

$$
n_{S B, t+1}^{d}=\left(1-\rho_{t}^{K}\right)\left(1-\rho_{t}^{O}\right)\left(1-\rho_{t}^{S}\right)\left(n_{S B, t}^{d}+n_{S E, t} v_{S E, t} q_{S E, t}+o_{S B, t} v_{S B, t} q_{S B, t}\right)
$$

gives the evolution of salaried employment in small firms from the labor demand perspective, where: $q_{S B, t}$ is the probability that a small firm fills a vacancy. From a labor supply perspective, at the start of a period $n_{S B, t}^{s}$ individuals are employed by small firms. Unemployed individuals find a job with a newly-formed small firm with probability $f_{S E, t}$ and they find a job with an existing small firm with probability $f_{S B, t}$. Therefore,

$$
n_{S B, t+1}^{s}=\left(1-\rho_{t}^{K}\right)\left(1-\rho_{t}^{O}\right)\left(1-\rho_{t}^{S}\right)\left[n_{S B, t}^{s}+u_{t}\left(f_{S E, t}+f_{S B, t}\right)\right]
$$


In equilibrium, $n_{S B, t}^{s}=n_{S B, t}^{d}=n_{S B, t}$.

Finally, unemployment at time $t$ is given by

$$
u_{t}=1-n_{L, t}-n_{S E, t}-n_{S B, t}-o_{S B, t} .
$$

Because the labor force is normalized to unity, $u_{t}$ is also the aggregate unemployment rate.

\subsubsection{Household Optimization}

In solving its optimization problem, the household takes all job-finding, -filling, and destruction probabilities as given. Also, we assume that from the perspective of small firms the household maximizes utility as a demander of labor. This assumption keeps the solution to the household's labor-supply and -demand problems explicitly decentralized.

The household's problem is to choose sequences of consumption $c_{t}$, the desired measure of self-employed individuals (achieved by spending resources on capital search) $n_{S E, t+1}$, the desired demand for salaried workers by small firms (achieved by vacancy posting) $n_{S B, t+1}^{d}$, the desired measure of small firm owners (also achieved by vacancy posting) $o_{S B, t+1}$, total expenditures on capital search $s_{K, t}$, vacancies posted per small firm $v_{S B, t}$, and vacancies posted per self-employed individual $v_{S E, t}$, in order to maximize $\mathbb{E}_{0} \sum_{t=0}^{\infty} \beta^{t} u\left(c_{t}\right)$, where: $\mathbb{E}$ is the expectation operator; $\beta \in(0,1)$ is the constant subjective discount factor; $u$ is the instantaneous utility function with $u^{\prime}(c)>0$ and $u^{\prime \prime}(c)<0$; and $c$ is consumption. Note that because there is no labor force participation or sectoral search-intensity decision, the household has no explicit choice over $n_{S B, t+1}^{s}$ and $n_{L, t+1}$. Instead, the household simply takes as given the labor supply side equations (4) and (8).

The household's maximization problem is subject to equations (1), (3), (5), (6), (7) and also to the household's budget constraint:

$$
c_{t}+\tau_{t}^{\kappa} \kappa\left(s_{K, t}\right)+T_{t}=\Pi_{S B, t}+\Pi_{S E, t}+\Pi_{L, t}+w_{S B, t} n_{S B, t}^{s}+w_{L, t} n_{L, t}+b u_{t},
$$

where: the price of consumption is normalized to unity and the household must pay lumpsum taxes $T_{t}$; the large firm, whose problem is described below, is owned by the household 
and its profits $\Pi_{L, t}$ are taken as given; individuals employed by the large firm earn the real wage $w_{L, t}$; individuals employed by small firms earn the real wage $w_{S B, t}$; unemployed individuals obtain the constant and exogenous per-period unemployment flow benefit $b$; the household spends resources $s_{K, t}$ at total cost $\kappa\left(s_{K, t}\right)$ to search for capital suppliers (large firms) that provide capital for self-employment ventures, with $\kappa^{\prime}\left(s_{K, t}\right)>0$ and $\kappa^{\prime \prime}\left(s_{K, t}\right) \geq 0$; $\tau_{t}^{\kappa}$ is a time-varying policy that equals 1 in steady state and decreases (increases) when total output is below (above) trend (thus, when output is below trend, the policy acts as a subsidy that reduces the cost of finding external financing to start a self-employment venture, i.e. this policy acts as a self-employment startup subsidy).

\subsubsection{Household Optimality Conditions}

As shown in the Appendix, the household's decision on $s_{K, t}$ to search for a capital supplier is given by

$$
\frac{\tau_{t}^{\kappa} \kappa^{\prime}\left(s_{K, t}\right)}{f_{K, t}}=\left(1-\rho_{t}^{K}\right) \mathbb{E}_{t} \Xi_{t+1 \mid t}\left\{p_{S E, t+1} z_{S E, t+1}-r_{S E, t+1}+\frac{\tau_{t+1}^{\kappa} \kappa^{\prime}\left(s_{K, t+1}\right)}{f_{K, t+1}}\right\}
$$

where $\Xi_{t+1 \mid t}=\beta u^{\prime}\left(c_{t+1}\right) / u^{\prime}\left(c_{t}\right)$ is the stochastic discount factor. This expression equates the expected marginal cost of spending resources to find capital to the expected marginal benefit. The latter is given by individual earnings in self-employment if the match takes place and becomes productive next period, $p_{S E} z_{S E}-r_{S E}$, plus the continuation value (see Finkelstein Shapiro, 2014). Note that the cost of posting vacancies during self-employment does not appear in this optimality condition because the household internalizes the fact that a self-employed individual may be able to become a small business owner in the future (the only relevant objects that affect the decision to enter self-employment is the revenue net of the cost of capital plus the continuation value of a capital relationship). The cost of posting vacancies will, in turn, affect the decision to transform a self-employment venture into a small salaried firm.

The household's optimal choice of transforming a self-employed firm into a small salaried 
firm is:

$$
\begin{array}{r}
\frac{1}{\left(1-\rho_{t}^{S}\right)\left(1-\rho_{t}^{K}\right)\left(1-\rho_{t}^{O}\right)}\left(\frac{\tau_{t}^{v_{S E}} \psi_{S E}}{q_{S E, t}}-\frac{\tau_{t}^{v_{S B}} \psi_{S B}}{q_{S B, t}}\right) \\
=\mathbb{E}_{t} \Xi_{t+1 \mid t}\left\{\begin{array}{c}
p_{S B, t+1} z_{S B, t+1} F_{O_{S B}}\left(n_{S B, t+1}, o_{S B, t+1}\right) \\
-r_{S B, t+1}-\left(p_{S E, t+1} z_{S E, t+1}-r_{S E, t+1}\right) \\
+\frac{1}{\left(1-\rho_{t+1}^{S}\right)}\left(\frac{\tau_{t+1}^{v} \psi_{S E}}{q_{S E, t+1}}-\frac{\tau_{t+1}^{v_{S B}} \psi_{S B}}{q_{S B, t+1}}\right)
\end{array}\right\} .
\end{array}
$$

The left-hand side of this expression captures the expected marginal cost, which in this case is given by the expected cost of posting a vacancy - a necessary condition to transition from being a self-employed individual to a small business owner - net of the cost of posting a vacancy faced by existing small firms (the latter is shown below and embodies the value of having an additional salaried worker as an existing small firm). The right-hand side of this expression gives the expected marginal benefit of becoming a small business owner and is comprised of two terms: the continuation value, and the net benefit of being a small business owner. In particular, the latter term is given by the difference between the marginal product of having a household member running a small business net of the cost of the matched unit of capital, $p_{S B} z_{S B} F_{o_{S B}}\left(n_{S B}, o_{S B}\right)-r_{S B}$, and self-employment revenue net of the cost of matched capital, $p_{S E} z_{S E}-r_{S E}$. Note that a self-employed individual is not only taking into account the net value of being a small business owner, but also the value of having a salaried worker as a small salaried firm, which is implicitly given by the term $\tau_{t}^{v_{S B}} \psi_{S B} / q_{S B, t}$.

Finally, the optimal choice of vacancies posted per existing small firm yields a standard job creation condition

$$
\frac{1}{\left(1-\rho_{t}^{K}\right)\left(1-\rho_{t}^{O}\right)\left(1-\rho_{t}^{S}\right)} \frac{\tau_{t}^{v_{S B}} \psi_{S B}}{q_{S B, t}}=\mathbb{E}_{t} \Xi_{t+1 \mid t}\left\{\begin{array}{c}
p_{S B, t+1} z_{S B, t+1} F_{n_{S B}}\left(n_{S B, t+1}, o_{S B, t+1}\right) \\
-\tau_{t+1}^{w_{S B}} w_{S B, t+1}+\frac{\tau_{t+1}^{v_{S B}} \psi_{S B}}{q_{S B, t+1}}
\end{array}\right\} .
$$

This expression simply equates the expected marginal cost of posting a vacancy to hire workers in a small firm to the expected marginal benefit. The latter includes the marginal product of labor net of the wage and the continuation value from the employment relationship. 


\section{$2.2 \quad$ Large Firms}

A representative large firm chooses desired large-firm employment (achieved by vacancy posting) $n_{L, t+1}$, total vacancies devoted to hiring workers $v_{L, t}$, total capital $k_{L, t+1}$, a target for the capital to be lent out to the self-employed $n_{S E, t+1}$, a target for the capital to be lent out to small businesses $o_{S B, t+1}$, and the fraction of capital used within the firm $\omega_{t}$, in order to maximize:

$$
\mathbb{E}_{0} \sum_{t=0}^{\infty} \Xi_{t \mid 0}\left\{\begin{array}{c}
p_{L, t} z_{L, t} \mathbb{F}\left(n_{L, t}, \omega_{t} k_{L, t}\right)+r_{S E, t} n_{S E, t}+r_{S B, t} o_{S B, t} \\
-\tau_{t}^{w_{L}} w_{L, t} n_{L, t}-\tau_{t}^{v_{L}} \psi_{L} v_{L, t}-i_{t}-\frac{\varphi_{k}}{2}\left(\frac{k_{L, t+1}}{k_{L, t}}-1\right)^{2} k_{L, t}
\end{array}\right\}
$$

where: $p_{L, t}$ is the price of large-firm output; $z_{L, t}$ is an exogenous sectoral productivity parameter; $\mathbb{F}(\cdot, \cdot)$ is the production function, which is increasing and concave in each of its arguments; $i_{t}$ is investment; $\psi_{L}$ is the fixed and exogenous flow cost of posting employment vacancies; and the last term reflects a standard capital adjustment cost. Also, similar to the case of small businesses, we introduce a time-varying policy that affects large-firm wages $\tau_{t}^{w_{L}}$, and another policy that affects the cost of hiring $\tau_{t}^{v_{L}}$, where both policies equal 1 in steady state and decrease (increase) when total output is below (above) trend. Note that, for a given stock of capital, a rise in $\omega_{t}$ implies a fall in the supply of capital to the self-employment sector.

The firm's optimization problem is subject to the perceived law of motion for the evolution of large-firm employment:

$$
n_{L, t+1}=\left(1-\rho_{t}^{L}\right)\left(n_{L, t}+v_{L, t} q_{L, t}\right),
$$

where: $q_{L, t}$ is a large firm's job filling probability; the perceived evolution of capital used in the self-employment sector:

$$
n_{S E, t+1}=\left(1-\rho_{t}^{K}\right)\left[\left(1-\left(1-\rho_{t}^{O}\right)\left(1-\rho_{t}^{S}\right) v_{S E, t} q_{S E, t}\right) n_{S E, t}+\rho_{t}^{O} o_{S B, t}+\left(1-\omega_{t}\right) k_{L, t} q_{K, t}\right],
$$

where: $q_{K, t}$ is the large firm's probability of forming a new capital supplier match; the 
perceived evolution of capital used by small businesses:

$$
o_{S B, t+1}=\left(1-\rho_{t}^{K}\right)\left(1-\rho_{t}^{O}\right)\left[o_{S B, t}+\left(1-\rho_{t}^{S}\right) v_{S E, t} q_{S E, t} n_{S E, t}\right]
$$

and the evolution of the firm's total capital stock (following Finkelstein Shapiro, 2014, and similar to Kurmann and Petrosky-Nadeau, 2007):

$$
\begin{gathered}
k_{L, t+1}=(1-\delta) \omega_{t} k_{L, t}+\left(\rho_{t}^{K}-\delta\right) n_{S E, t}+\left[\left(1-\left(1-\rho_{t}^{K}\right)\left(1-\rho_{t}^{O}\right)\right)-\delta\right] o_{S B, t}+i_{t} \\
+\left[(1-\delta)-\left(1-\rho_{t}^{K}\right) q_{K, t}\right]\left(1-\omega_{t}\right) k_{L, t}
\end{gathered}
$$

where: $\delta$ is the exogenous depreciation rate of capital.

\subsubsection{Large-Firm Optimality Conditions}

The firm's choice of total capital satisfies a standard capital Euler equation:

$$
\left[1+\varphi_{k}\left(\frac{k_{L, t+1}}{k_{L, t}}-1\right)\right]=\mathbb{E}_{t} \Xi_{t+1 \mid t}\left\{\begin{array}{c}
p_{L, t+1} z_{L, t+1} \mathbb{F}_{\omega_{L} k_{L}}\left(n_{L, t+1}, \omega_{t} k_{L, t+1}\right) \\
+(1-\delta)-\frac{\varphi_{k}}{2}\left(\frac{k_{L, t+2}}{k_{L, t+1}}-1\right)^{2}+\varphi_{k}\left(\frac{k_{L, t+2}}{k_{L, t+1}}-1\right) \frac{k_{L, t+2}}{k_{L, t+1}}
\end{array}\right\} .
$$

A standard job creation condition for large firm salaried employment also obtains:

$$
\frac{\tau_{t}^{v_{L}} \psi_{L}}{q_{L, t}}=\left(1-\rho_{t}^{L}\right) \mathbb{E}_{t} \Xi_{t+1 \mid t}\left\{p_{L, t+1} z_{L, t+1} \mathbb{F}_{n_{L}}\left(n_{L, t+1}, \omega_{t} k_{L, t+1}\right)-\tau_{t+1}^{w_{L}} w_{L, t+1}+\frac{\tau_{t+1}^{v_{L}} \psi_{L}}{q_{L, t+1}}\right\}
$$

Finally, the firm's optimal decision to devote capital to forming new capital matches satisfies

$$
\frac{p_{L, t} z_{L, t} \mathbb{F}_{\omega_{L} k_{L}}\left(n_{L, t}, \omega_{t} k_{L, t}\right)+\left(1-\rho_{t}^{K}\right) q_{K, t}}{q_{K, t}}=\left(1-\rho_{t}^{K}\right) \mathbb{E}_{t} \Xi_{t+1 \mid t} \mathbf{J}_{S E, t+1}
$$

where: $\mathbf{J}_{S E}$ is the large firm's capital gains from a new capital match (see the Appendix for further details). This last expression equates the expected marginal cost of devoting an additional unit of capital to matching to the expected marginal benefit. The former is comprised of two terms: the expected marginal cost of that unit of capital within the large firm sector, $\frac{p_{L, t} z_{L, t} \mathbb{F}_{\omega k_{L}, t}}{q_{K, t}}$, and the opportunity cost of keeping a matched unit of capital within the firm until it becomes active in the self-employment sector next period, $\left(1-\rho_{t}^{K}\right)$. The 
expected marginal benefit is given by the value of having a capital relationship next period. Note that $\mathbf{J}_{S E}$ takes into account the value of becoming a small firm in future periods (see the Appendix for more details). ${ }^{6}$

\subsection{Matching Processes}

Let $m_{S E, t}=m_{S E}\left(v_{S E, t} n_{S E, t}, u_{t}\right), m_{S B, t}=\tau_{t}^{m_{S B}} m_{S B}\left(v_{S B, t} O_{S B, t}, u_{t}\right), m_{L, t}=\tau_{t}^{m_{L}} m_{L}\left(v_{L}, u_{t}\right)$ and $m_{K, t}=m_{K}\left(\left(1-\omega_{t}\right) k_{L, t}, s_{K, t}\right)$ be standard matching functions that are increasing and concave in each of their arguments. $\tau_{t}^{m_{L}}$ and $\tau_{t}^{m_{S B}}$ are cyclical policies that equal 1 in steady state, but improve (reduce) matching efficiency for large and existing small firms, respectively, relative to trend during downturns (upturns). This policy specification tractably captures the expansion (contraction) of government-provided job intermediation services during recessions (expansions).

The matching functions imply the following job-finding probabilities: $f_{S E, t}=\frac{m_{S E, t}}{u_{t}}$; $f_{S B, t}=\frac{m_{S B, t}}{u_{t}} ; f_{L, t}=\frac{m_{L, t}}{u_{t}} ;$ and $f_{K, t}=\frac{m_{K, t}}{s_{K, t}}$. The matching functions also imply the following job-filling probabilities: $q_{S E, t}=\frac{m_{S E, t}}{v_{S E, t} n_{S E, t}} ; q_{S B, t}=\frac{m_{S B, t}}{v_{S B, t} o_{S B, t}} ; q_{L, t}=\frac{m_{L, t}}{v_{L, t}} ;$ and $q_{K, t}=\frac{m_{K, t}}{\left(1-\omega_{t}\right) k_{L, t}}$.

Labor market tightness for potential new small firms is $\theta_{S E, t} \equiv \frac{v_{S E, t} n_{S E, t}}{u_{t}}$, and labor market tightness for existing small firms is $\theta_{S B, t} \equiv \frac{v_{S B, t} o_{S B, t}}{u_{t}}$. Large-firm labor market tightness is $\theta_{L, t} \equiv \frac{v_{L, t}}{u_{t}}$. In turn, capital market tightness is $\theta_{K, t} \equiv \frac{s_{K, t}}{\left(1-\omega_{t}\right) k_{L, t}}$. All salaried job-finding probabilities are increasing in market tightness, while all salaried job-filling probabilities are decreasing in market tightness. Given our definition of capital market tightness $\theta_{K, t}, f_{K, t}$ $\left(q_{K, t}\right)$ is decreasing (increasing) in capital market tightness.

\subsection{Wages}

For the sake of brevity, the value functions used in the determination of Nash prices as well as the statements of all Nash problems are relegated to the Appendix. From the perspective of a large firm: the value of having an additional salaried worker is $\mathbf{J}_{L, t}$; the value of having a capital relationship with a self-employed individual is $\mathbf{J}_{S E, t}$; and the value of having a capital

\footnotetext{
${ }^{6}$ The condition that characterizes the large firm's optimal choice over the desired measure of small business owners is given by the value function of having an additional unit of matched capital in the small firm sector. For expositional brevity, this value function is included in the Appendix.
} 
relationship with a small firm is $\mathbf{J}_{S B, t}$. From the perspective of the small firm sector: the value of having an additional salaried worker is $\mathbf{J}_{O S B, t}$; and the value of having an additional capital relationship with large firms is $\mathbf{W}_{O S B, t}$. From the perspective of the household, the values of having a household member in salaried employment in a large firm, in salaried employment in a small firm, in self-employment, and in unemployment, are, respectively, $\mathbf{W}_{L, t}, \mathbf{W}_{S B, t}, \mathbf{W}_{S E, t}$, and $\mathbf{W}_{U, t} \cdot \chi_{L} \in(0,1)$ and $\chi_{S B} \in(0,1)$ are, respectively, the bargaining power of workers negotiating with large firms and of workers negotiating with small firms. $\chi_{S E} \in(0,1)$ and $\chi_{O} \in(0,1)$ are, respectively, the bargaining power of self-employed and small business owners.

The implicit expressions for the Nash wages are given by

$$
\frac{\chi_{L}}{\left(1-\chi_{L}\right) \tau_{t}^{w_{L}}} \mathbf{J}_{L, t}=\left(\mathbf{W}_{L, t}-\mathbf{W}_{U, t}\right)
$$

for $w_{L, t}$ and

$$
\frac{\chi_{S B}}{\left(1-\chi_{S B}\right) \tau_{t}^{w_{S B}}} \mathbf{J}_{O S B, t}=\left(\mathbf{W}_{S B, t}-\mathbf{W}_{U, t}\right)
$$

for $w_{S B, t}$. The implicit expressions for the Nash rental rates are given by

$$
\frac{\chi_{K}}{\left(1-\chi_{K}\right)}\left(\mathbf{J}_{S E, t}-(1-\delta)\right)=\left(\mathbf{W}_{S E, t}-\mathbf{W}_{U, t}\right)
$$

for $r_{S E, t}$ and

$$
\frac{\chi_{O}}{\left(1-\chi_{O}\right)}\left(\mathbf{J}_{S B, t}-(1-\delta)\right)=\left(\mathbf{W}_{O S B, t}-\mathbf{W}_{U, t}\right)
$$

for $r_{S B, t}$. Note that the outside option of large firms is the value of a unit of capital net of depreciation, $(1-\delta)$ (Finkelstein Shapiro, 2014).

\subsection{Closing the Model}

Final output results as follows. We assume that composite output from the small firm and self-employment sectors is given by $y_{S, t}=y_{S}\left(y_{S B, t}, y_{S E, t}\right)$. In turn, final output aggregates large-firm output and the preceding composite output using the production function

$y_{t}=y\left(y_{L, t}, y_{S_{t}}\right)$. Turning toward profit maximization, because the price of final output is 
normalized to 1 , the problem of the final goods producer is:

$$
\max _{y_{L, t}, y_{S B, t}, y_{S E, t}}\left\{y_{t}-p_{L, t} y_{L, t}-p_{S B, t} y_{S B, t}-p_{S E, t} y_{S E, t}\right\}
$$

The government uses lump-sum taxes to finance expenditures, and its budget constraint is

$$
\begin{gathered}
T_{t}=b u_{t}+\left(1-\tau_{t}^{v_{L}}\right) \psi_{L} v_{L, t}+\left(1-\tau_{t}^{v_{S E}}\right) \psi_{S E} v_{S E, t} n_{S E, t}+\left(1-\tau_{t}^{v_{S B}}\right) \psi_{S B} v_{S B, t} O_{S B, t} \\
+\left(1-\tau_{t}^{\kappa}\right) \kappa\left(s_{K, t}\right)+g_{t}+\left(1-\tau_{t}^{w_{L}}\right) w_{L, t} n_{L, t}+\left(1-\tau_{t}^{w_{S B}}\right) w_{S B, t} n_{S B, t} \\
\quad+\left(\tau_{t}^{m_{L}}-1\right) m_{L}\left(v_{L}, u_{t}\right)+\left(\tau_{t}^{m_{S B}}-1\right) m_{S B}\left(v_{S B, t} o_{S B, t}, u_{t}\right)
\end{gathered}
$$

Above, $g_{t}$ is exogenous government spending and the last two terms represent the fiscal cost of job intermediation services. In what follows, we assume that $g_{t}$ is constant. ${ }^{7}$

The resource constraint of the economy is given by

$$
\begin{gathered}
y_{t}=c_{t}+g_{t}+i_{t}+\kappa\left(s_{K, t}\right)+\psi_{L} v_{L, t}+\psi_{S E} v_{S E, t} n_{S E, t}+\psi_{S B} v_{S B, t} o_{S B, t} \\
+\frac{\varphi_{k}}{2}\left(\frac{k_{L, t+1}}{k_{L, t}}-1\right)^{2} k_{L, t}+\left(\tau_{t}^{m_{L}}-1\right) m_{L}\left(v_{L}, u_{t}\right)+\left(\tau_{t}^{m_{S B}}-1\right) m_{S B}\left(v_{S B, t} o_{S B, t}, u_{t}\right),
\end{gathered}
$$

where the cost of posting vacancies, searching for capital, and providing job intermediation services are resource costs.

\subsection{Definition of Competitive Equilibrium}

Taking the stochastic processes $\left\{z_{L, t}, z_{S E, t}, z_{S B, t}\right\}$ and the policies as given, the allocations and prices $\left\{n_{L, t}, n_{S B, t}, o_{S B, t}, n_{S E, t}, u_{t}, \theta_{K, t}, \theta_{S E, t}, \theta_{S B, t}, \omega_{t}, k_{L, t}, \theta_{L, t}, c_{t}, w_{L, t}, w_{S B, t}, r_{S E, t}\right.$, $\left.r_{S B, t}, T_{t}, y_{t}\right\}$ and $\left\{p_{L, t}, p_{S B, t}, p_{S E, t}\right\}$ satisfy: the law of motion for salaried employment

\footnotetext{
${ }^{7}$ As part of our robustness checks, we analyze the case where cyclical policies are financed through government debt. We also consider a case where the cyclical subsidies for small firms are financed through an increase in large-firm payroll taxes. This last case is particularly relevant when the informal sector is large, as is the case in most developing countries. The main results and conclusions remain the same under these alternative scenarios. Also, the assumption of lump-sum taxation is not restrictive considering that some developing countries used commodity revenue to finance part of their stimulus packages. One example is Mexico, which used oil revenue as a source of financing for some of its stimulus programs during the global financial crisis.
} 
in large firms; the law of motion for small firm salaried employment; the law of motion for small business owners; the law of motion for self-employed individuals; the definition of unemployment; the household's optimal choice to search for capital suppliers; the optimal decision to transition from self-employment into small business owner status; the job creation decision by small business owners; the capital supply decision by large firms; the capital Euler equation of large firms; the job creation decision by large firms; the resource constraint; the Nash wage for salaried workers in large firms; the Nash wage for small firm salaried workers; the Nash rental rate for self-employed individuals; the Nash rental rate for small business owners; the three relative prices of sectoral output; the government budget constraint; and the definition of total output.

\section{Calibration}

We assume a time period of 1 quarter. In addition, we choose Mexico as our benchmark reference since this country has quality data on labor flows and existing studies provide well-documented stylized facts about cyclical employment dynamics.

\subsection{Functional Forms and Shocks}

Final output is given by a constant elasticity of substitution (CES) aggregate of large firm output and composite output from the self-employment and small firm sectors:

$$
y_{t}=\left[\gamma_{a} y_{L, t}^{\phi_{a}}+\left(1-\gamma_{a}\right) y_{S, t}^{\phi_{a}}\right]^{\frac{1}{\phi_{a}}}
$$

where $\gamma_{a} \in(0,1)$ and $\phi_{a} \leq 1$. In turn, composite output from the small firm and selfemployment sectors is given by the CES aggregate:

$$
y_{S, t}=\left[\gamma_{s} y_{S B, t}^{\phi_{s}}+\left(1-\gamma_{s}\right) y_{S E, t}^{\phi_{s}}\right]^{\frac{1}{\phi_{s}}}
$$


where $\gamma_{s} \in(0,1)$ and $\phi_{s} \leq 1 .^{8}$ The production function for large firms is Cobb-Douglas: $\mathbb{F}\left(n_{L, t}, \omega_{t} k_{L, t}\right)=\left(n_{L, t}\right)^{1-\alpha_{L}}\left(\omega_{t} k_{L, t}\right)^{\alpha_{L}}$, where $\alpha_{L} \in(0,1)$. The production function for the aggregate small firm sector is also Cobb-Douglas: $F\left(n_{S B, t}, o_{S B, t}\right)=\left(n_{S B, t}\right)^{1-\alpha_{S B}}\left(o_{S B, t}\right)^{\alpha_{S B}}$, where $\alpha_{L} \in(0,1)$. We assume that $\alpha_{L}>\alpha_{S B}$ so that, in line with existing evidence, production in large firms is more capital intensive. In each intermediate production sector productivity follows an $\mathrm{AR}(1)$ process with a common aggregate shock:

$$
\ln z_{i, t}=\left(1-\rho_{z_{i}}\right) \ln \left(\bar{z}_{i}\right)+\rho_{z_{i}} \ln z_{L, t-1}+\varepsilon_{t}^{z}
$$

where for $i \in\{L, S B, S E\}: \bar{z}_{i}$ is a constant and we assume that $\forall i \rho_{z_{i}}=\rho_{z}$; and $\varepsilon_{t}^{z} \sim$ $N\left(0, \sigma_{z}^{2}\right)$ denotes the aggregate productivity shock (i.e., common to all sectoral productivity processes). Therefore, while all sectors are subject to a common productivity shock, each sector's steady state productivity can potentially differ.

We follow related literature and assume that all matching functions are Cobb-Douglas. In particular, $m_{L, t}=\tau_{t}^{m_{L}} M_{L}\left(u_{t}\right)^{\xi_{L}}\left(v_{L, t}\right)^{1-\xi_{L}}, m_{S B, t}=\tau_{t}^{m_{S B}} M_{S B}\left(u_{t}\right)^{\xi_{S B}}\left(v_{S B, t} o_{S B, t}\right)^{1-\xi_{S B}}$, $m_{S E, t}=M_{S E}\left(u_{t}\right)^{\xi_{S E}}\left(v_{S E, t} n_{S E, t}\right)^{1-\xi_{S E}}$, and $m_{K, t}=M_{K}\left(s_{K, t}\right)^{\xi_{K}}\left(\left(1-\omega_{t}\right) k_{L, t}\right)^{1-\xi_{K}}$ where, for $j \in\{L, S B, S E, K\}: M_{j}$ is the matching efficiency parameter; and $\xi_{j}$ is the matching elasticity parameter. For tractability, we assume that all separation probabilities are countercyclical relative to fluctuations in total output so that

$$
\rho_{t}^{j}=\rho_{s s}^{j}\left[\exp \left(\eta_{\rho^{j}}\left(1-\frac{y_{t}}{y_{s s}}\right)\right)\right]
$$

for $j \in\{L, K, O, S\}$, where: $\eta_{\rho^{j}}>0$ determines the sensitivity of the separation probabilities to output deviations from trend; $\rho_{s s}^{j}$ is the steady-state job destruction probability; and $y_{s s}$ is steady-state final output. This specification implies that separation probabilities increase (decrease) above their steady state values when output is below (above) trend. Finally, with regards to the household, we assume that the cost of searching for capital is $\kappa\left(s_{K, t}\right)=$ $\psi_{K}\left(s_{K, t}\right)^{\eta_{K}}$, with $\psi_{K}>0$ and $\eta_{K} \geq 1$. In addition, the household's utility function is characterized by constant relative risk aversion so that $u\left(c_{t}\right)=\frac{c_{t}^{1-\sigma}}{1-\sigma}$.

\footnotetext{
${ }^{8}$ The elasticities of substitution are $\frac{1}{1-\phi_{a}}$ and $\frac{1}{1-\phi_{s}}$, respectively.
} 


\subsection{Parameters From Related Literature}

The elasticity of substitution parameters in the CES aggregator functions are set to 0.7 so that production inputs are somewhat imperfectly substitutable. ${ }^{9}$ The persistence parameters for each of the sectoral productivity shocks are set to 0.92 . The capital depreciation rate $\delta$ is in line with other studies on Mexico. Based on Busso, Fazio, and Levy (2012), we compute productivity differentials by type of firm so that the model is consistent with the large productivity differences that exist between self-employed firms, small firms, and large firms (see the Appendix for further details).

Table 7:

Parameterization for Benchmark Economy, Part I

\begin{tabular}{ccll}
\hline \hline Parameter & Value & Parameter Description & \multicolumn{1}{c}{ Parameter Source } \\
\hline$\alpha_{L}$ & 0.32 & Capital Share, Large Firms & DSGE Literature \\
$\alpha_{S B}$ & 0.27 & Capital Share, Small Firms & - \\
$b$ & 0 & Unempl. Insurance & No Unempl. Benefits \\
$\beta$ & 0.985 & Discount Factor & DSGE Literature \\
$\delta$ & 0.025 & Capital Depreciation & DSGE Literature \\
$\eta_{K}$ & 1 & Curvature Search Cost & Search Literature \\
$\chi$ & 0.50 & Bargaining Power & Search Literature \\
$\xi$ & 0.50 & Matching Elasticity & Search Literature \\
$\phi_{a}$ & 0.7 & Elasticity Param. & Assumption \\
$\phi_{s}$ & 0.7 & Elasticity Param. & Assumption \\
$\rho_{s s}^{L}$ & 0.05 & Sep. Prob., Large Firms & Bosch, Maloney (2008) \\
$\rho_{s s}^{K}$ & 0.03 & Sep. Prob., SE & Bosch, Maloney (2008) \\
$\rho_{s s}^{S}$ & 0.03 & Sep. Prob., Small Firms & Assumption \\
$\rho_{z_{L}}$ & 0.92 & Autocorrelation of $z_{L}$ & DSGE Literature \\
$\rho_{z_{S B}}$ & 0.92 & Autocorrelation of $z_{S B}$ & DSGE Literature \\
$\rho_{z_{S E}}$ & 0.92 & Autocorrelation of $z_{S E}$ & DSGE Literature \\
$\sigma$ & 2 & CRRA Utility Parameter & DSGE Literature \\
$\bar{z}_{L}$ & 5.17 & Large Firm Productivity & Busso et al. (2012) \\
$\bar{z}_{S B}$ & 3.57 & Small Firm Productivity & Busso et al. (2012) \\
$\bar{z}_{S E}$ & 1 & SE Productivity & Normalization \\
\hline
\end{tabular}

Most Latin American and other developing countries, including Mexico, do not have a national unemployment insurance scheme, so we set $b$ to 0 . The subjective discount factor $\beta$ is set to 0.985 , in line with the literature (Boz, Durdu, and Li, 2012). The curvature of capital search is $\eta_{K}=1$ (assuming that the cost of searching for capital is convex does not change our main conclusions). The coefficient of relative risk aversion is set to 2 . We set the bargaining power for salaried workers, self-employed individuals, and small business owners

\footnotetext{
${ }^{9}$ We explore different parameterizations in the Appendix.
} 
to 0.5 . The matching elasticities are set 0.5 so that the Hosios condition holds (Hosios, 1990). The steady-state separation probabilities are based on Bosch and Maloney (2008). ${ }^{10}$

\subsection{Calibrated Parameters}

Calibrated parameters are summarized in Table 8. The matching efficiency parameters are chosen so that the model is in line with the allocation of employment across firms in the data. Our mapping between the data and the model is based on evidence on firm size and formality/legality status for Mexico (Busso, Fazio, and Levy, 2012), and yields the following distribution of individuals across employment states: the self-employed (or micro firms) represent 16 percent of the labor force; small business owners represent 7 percent; salaried workers in small firms represent 30 percent; and salaried workers in large firms account for 42 percent of the labor force. ${ }^{11}$

Table 8:

Parameterization for Benchmark Economy, Part II

\begin{tabular}{ccll}
\hline \hline Parameter & Value & \multicolumn{1}{c}{ Parameter Description } & \multicolumn{1}{c}{ Target } \\
\hline$g$ & 0.0967 & Steady State Gov. Spending & 10.2 percent of output \\
$M_{L}$ & 0.111 & Large Firm Match. Eff. & $n_{L}=0.42$ \\
$M_{K}$ & 0.045 & SE Match. Eff. & $n_{S E}=0.16$ \\
$M_{S B}$ & 0.213 & Old Small Firm Match. Eff. & $o_{S B}=0.07$ \\
$M_{S E}$ & 0.027 & New Small Firm Match. Eff. & $n_{S B}=0.30$ \\
$\varphi_{k}$ & 0.496 & Capital Adj. Cost Param. & $\sigma_{p_{K, t}^{u}}=9.4$ \\
$\psi_{L}$ & 0.027 & Large Firm Vacancy Cost & 3.5 percent of $w_{L}$ \\
$\psi_{K}$ & 0.735 & Capital Search Cost & 3 months of $w_{S B}$ \\
$\psi_{S B}$ & 0.026 & Small Firm Vacancy Cost & 3.5 percent of $w_{S B}$ \\
$\psi_{S E}$ & 0.026 & SE Vacancy Cost & 3.5 percent of $w_{S B}$ \\
$\rho_{s s}^{O}$ & 0.022 & Destruction Rate, Small Firms & $\left(1-\rho^{S B}\right)=0.92$ \\
$\eta_{s s}^{L}$ & 1.27 & Sensitivity, Sep. prob. $\rho_{t}^{L}$ & $\frac{\sigma_{F \rightarrow U}}{\sigma_{I \rightarrow U}}=1.22$ \\
$\eta_{s s}^{K}$ & 1.00 & Sensitivity, Sep. prob. $\rho_{t}^{K}$ & Assumption \\
$\eta_{s s}^{O}$ & 1.00 & Sensitivity, Sep. prob. $\rho_{t}^{O}$ & Assumption \\
$\eta_{s s}^{S}$ & 1.00 & Sensitivity, Sep. prob. $\rho_{t}^{S}$ & Assumption \\
$\sigma_{z}$ & 0.0173 & SD Productivity Shock & $\sigma_{y}=2.39$ \\
$\gamma_{a}$ & 0.192 & CES Parameter & $\underline{p_{L} y_{L}}=0.55$ \\
$y$ & $\frac{p_{S B} y_{S B}}{y}=0.33$ \\
$\gamma_{s}$ & 0.453 & CES Parameter & \\
\hline
\end{tabular}

\footnotetext{
${ }^{10}$ For the salaried separation rate in large firms we take into account that a small share of workers in these firms is informal using existing evidence on the share of labor informality by firm size.

${ }^{11}$ Total self-employment in Mexico, which includes small business owners and own-account workers, is around 23 percent. Based on Perry et al. (2007) and others, between 65 and 70 percent of the self-employed are own-account workers (the remaining share being mostly individuals who operate small firms). This yields a self-employment (or own-account) share of 16 percent.
} 
The cost of adjusting capital is set to replicate the volatility of the probability of entering self-employment from unemployment (Bosch and Maloney, 2008). We set the cost of posting vacancies in small and large firms to 3.5 percent of sectoral wages (Levy, 2007). ${ }^{12}$ The perunit cost of searching for capital is set to 3 months of (small firm) wages, in line with the evidence in McKenzie and Woodruff (2006) (the results do not change if we assume much lower costs).

We set the steady-state job destruction probability of small firms $\rho_{s s}^{O}$ so that the separation probability for small firm workers (a combination of $\rho^{K}, \rho^{O}$, and $\rho^{S}$ ) is 8 percent, in line with the evidence on informal separation probabilities (Bosch and Maloney, 2008). To establish the sensitivity of separation probabilities to output deviations, we fix $\eta_{s s}^{K}, \eta_{s s}^{O}$, and $\eta_{s s}^{S}$ to 1 . In turn, we set $\eta_{s s}^{L}$ to capture the volatility of transitions from formal salaried employment to unemployment relative to the volatility of transitions from informal salaried employment to unemployment from Bosch and Maloney (2008). ${ }^{13}$

We calibrate the standard deviation of the aggregate productivity shock to match the standard deviation of Mexican real GDP for the years 1993 through 2007. In addition, we calibrate the steady-state government spending-output ratio to be 10.2 percent of output, which is representative of the Mexican economy.

\section{Quantitative Analysis}

To compare the model to the data, we use Mexican time series from 1993:Q1 to 2007:Q4 for output, consumption, and unemployment to compute second moments, as well as the evidence in Bosch and Maloney (2008) and Fernández and Meza (2014) for the labor market. The output, consumption, and unemployment series are obtained from the Federal Reserve

\footnotetext{
${ }^{12}$ Neither of these costs include the cost of hiring regulations. The results remain the same if we assume that the cost of posting vacancies for large firms includes the cost of hiring regulations, or if we assume a different calibration target for small firm vacancy postings.

${ }^{13}$ Since we do not have data on separation rates by firm size, this assumes that a majority of informal salaried workers are in small firms, which is consistent with the evidence (Perry et al., 2007). The model is unable to generate the volatility of separation rates in the data without running into convergence problems. Targeting the relative volatility of transitions from self-employment to unemployment yields qualitatively similar results and generates additional unemployment volatility, but significantly reduces the countercyclicality of self-employment. However, the main conclusions do not change.
} 
Bank of Saint Louis' FRED database. ${ }^{14}$

\subsection{Aggregate Dynamics without Policy}

Table 9 shows that qualitatively and quantitatively the model can match several stylized facts about business cycles and labor-market dynamics that we do not explicitly target. The model captures the countercyclicality of unemployment and self-employment, and also generates a relative volatility of unemployment higher than 1, which is difficult to generate in standard search models. The model also delivers a higher volatility in the job-finding probability in large firms relative to small firms that is broadly in line with the data.

Table 9:

Business Cycle Statistics: Data vs. Model

\begin{tabular}{ccc}
\hline \hline Targeted Second Moments & Data & Benchmark Model \\
\hline$\sigma_{y_{t}}$ & 2.39 & 2.39 \\
$\sigma_{f_{K, t}^{u}}^{u}$ & 9.40 & 9.40 \\
$\sigma_{\rho_{t}^{S B}} / \sigma_{\rho_{t}^{L}}$ & 1.22 & 1.23 \\
\hline$\sigma_{c_{t}} / \sigma_{y_{t}}$ & Data & Benchmark Model \\
$\sigma_{i_{t}} / \sigma_{y_{t}}$ & 1.13 & 0.56 \\
$\sigma_{u, t} / \sigma_{y_{t}}$ & 2.78 & 7.54 \\
$\sigma_{n_{L, t}} / \sigma_{n_{S B, t}}$ & 6.28 & 1.31 \\
$\sigma_{f_{L, t}} / \sigma_{\left(f_{S B, t}+f_{S E, t}\right)}$ & {$[1.00,1.05]$} & 0.92 \\
$\rho\left(n_{L, t}, y_{t}\right)$ & 2.18 & 2.29 \\
$\rho\left(n_{S B, t}, y_{t}\right)$ & {$[0.740,0.840]$} & 0.778 \\
$\rho\left(n_{S E, t}, y_{t}\right)$ & $-0.470,0.740]$ & 0.767 \\
$\rho\left(u_{t}, y_{t}\right)$ & -0.450 & -0.886 \\
$\rho\left(f_{L, t}, y_{t}\right)$ & -0.889 & -0.706 \\
$\rho\left(f_{S B, t}+f_{S E, t}, y_{t}\right)$ & 0.798 & 0.984 \\
$\rho\left(f_{K, t}^{u}, y_{t}\right)$ & 0.366 & 0.524 \\
$\rho\left(y_{t}, y_{t-1}\right)$ & -0.433 & -0.538 \\
$\rho\left(u_{t}, u_{t-1}\right)$ & 0.846 & 0.734 \\
& 0.878 & 0.748 \\
\hline
\end{tabular}

The cyclical correlation of large-firm employment and output and the probability of entering self-employment from unemployment are also consistent with the evidence. Finally, the cyclical correlation between the job-finding probability in large firms is higher than the one in small firms. The fact that the cyclical correlation of the job-finding probabilities

\footnotetext{
${ }^{14} \mathrm{We}$ log-linearize the model around the non-stochastic steady-state and implement a first-order approximation. We simulate the model for 2100 periods, discard the first 100 periods, and apply the Hodrick-Prescott filter with smoothing parameter 1600 to the simulated series to obtain the data's cyclical component and compute second moments. We use Dynare for all dynamic simulations.
} 
for salaried workers is particularly high is due to the presence of a single aggregate shock driving the model's dynamics. Introducing (correlated) sectoral shocks would allow us to quantitatively match the cyclical correlation of these finding probabilities in the data.

\subsection{Policy Experiments}

We compare the response of the economy to a negative aggregate productivity shock when no labor market policies are in place - the no-policy scenario - to the response under the earlier noted set of cyclical labor market policies. We assume that these policies respond to fluctuations in aggregate productivity as follows. For $j \in\left\{v_{L}, v_{S B}, v_{S E}, \kappa, m_{L}, m_{S B}, w_{L}\right.$, $\left.w_{S B}\right\}$

$$
\tau_{t}^{j}=\exp \left[\tau_{s s}^{j}\left(\frac{y_{t}}{y_{s s}}-1\right)\right],
$$

where: $\tau_{s s}^{j} \geq 0$ captures the intensity of the policy (for a related approach, see Canzoneri et al., 2011).

The specification in equation (9) has several attractive features. First, given how we introduced the policies in the model, $\tau_{t}^{j}$ is purely cyclical in nature and has no impact on steady-state allocations. Second, for $\tau_{s s}^{j} \geq 0$, the policy acts as a subsidy when output is below trend and as a tax when output is above trend, so that the government budget is always balanced. ${ }^{15}$ Third, in the case of a negative aggregate shock, the policy becomes active on impact and exhibits endogenous persistence, where the latter is determined by the severity and length of the recession. We calibrate each of the individual policies $\tau_{s s}^{j}$ to obtain a stimulus of 0.2 percent of output in the period of the negative aggregate shock. This fiscal package is in line with the size of the labor market measures introduced in Mexico as part of the stimulus package during the financial crisis (ILO, 2011). ${ }^{16}$

\footnotetext{
${ }^{15}$ While subsidies for micro and small firms may be easier to implement during downturns (via cash transfers, for example), recovering the revenue spent on these subsidies via the same instruments during expansions may be harder if most small firms are informal. If we assume that micro and small-firm subsidies are financed through a higher payroll tax on larger firms, the aggregate benefits from these subsidies are more subdued. As an example, we discuss the case of small-firm wage subsidies financed through payroll taxes on large firms in the Appendix.

${ }^{16}$ Recall that policy is endogenously determined once the shock takes place, which implies that the total fiscal cost in present value terms (once the economy returns back to steady state) is around 2.5 percent of GDP. Assuming a smaller fiscal package of 0.1 percent of output on impact, which naturally also delivers a lower total fiscal cost in present value terms of around 1.45 percent of GDP, yields very similar results across
} 


\subsection{Main Results}

Figures 1 and 2 show the impulse responses of key variables to a one standard deviation negative aggregate productivity shock. All impulse responses (including the ones in the Appendix) are in percent deviations from steady state. Along the figures' columns a particular policy is in place, and the figures' rows show a particular variable's response.
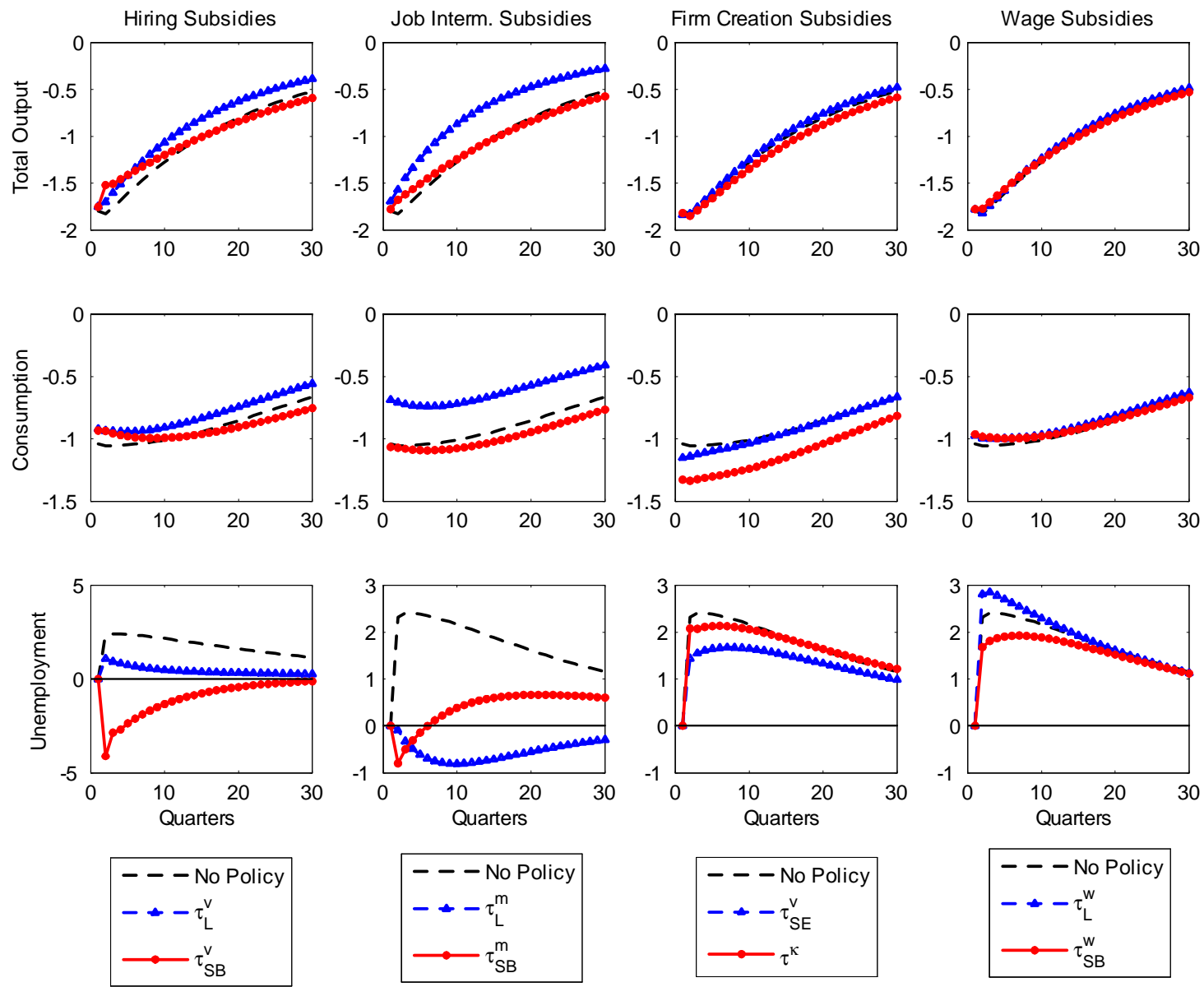

Figure 1

Response to a 1 percent negative productivity shock (quarters after shock):

Total output, consumption, and unemployment.

We focus on total output (first row of Figure 1), consumption (second row of Figure 1), the unemployment rate (third row of Figure 1), the average wage (that is, the employmentweighted average of wages in large and small firms; first row of Figure 2), subsidy rates policies. 
(second row of Figure 2), and the fiscal cost as a percent of GDP (third row of Figure 2). For reference, the figures also show impulse responses of variables under the benchmark (nopolicy) scenario. Inspection of Figures 1 and 2 implies that, for a fiscal package of given size, there is considerable variation in the effect that different policies have on aggregate variables, with some policies being detrimental to the recovery process.
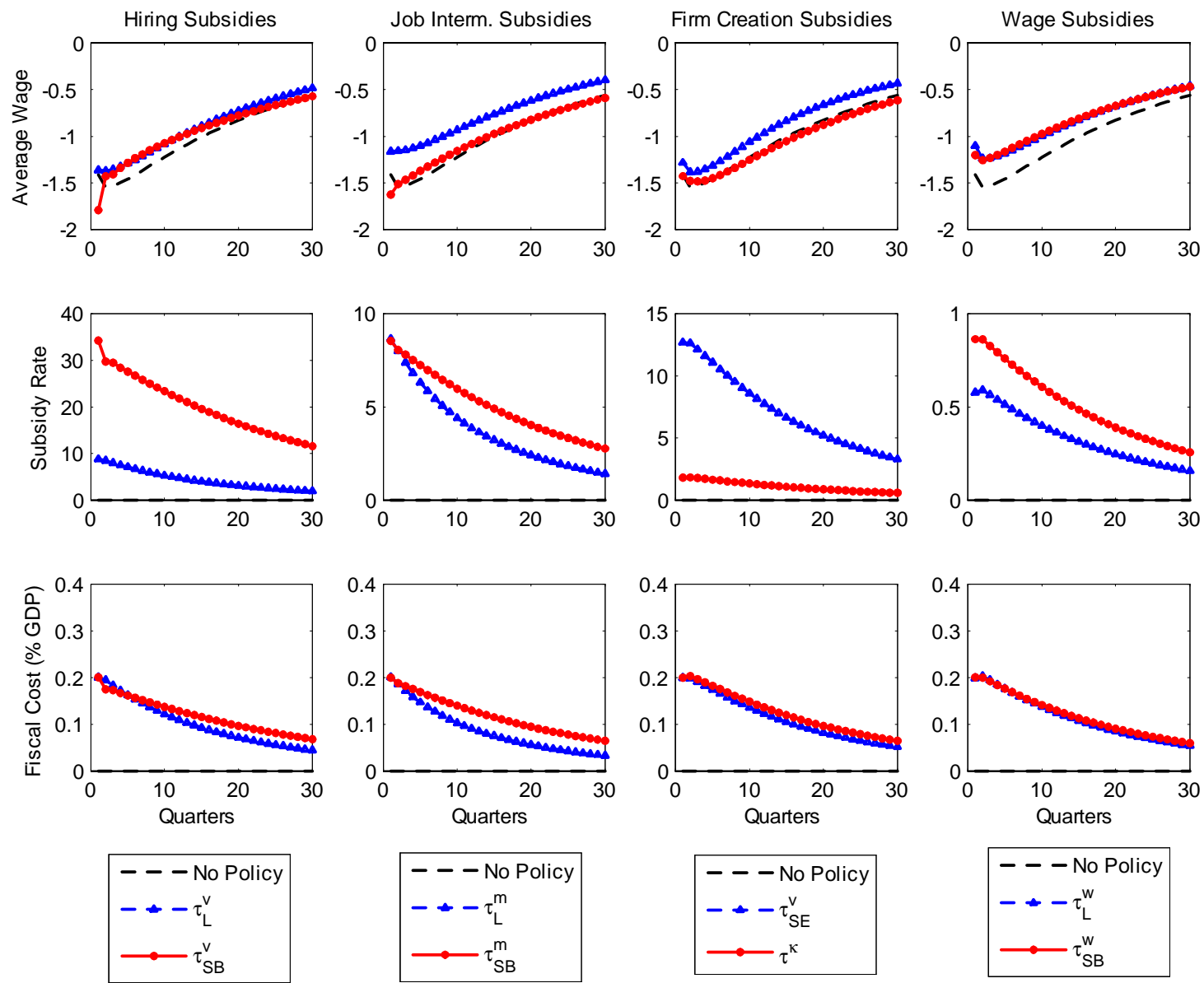

Figure 2

Response to a 1 percent negative productivity shock (quarters after shock): Average wage, subsidy rate, and fiscal cost as percent of GDP.

\subsubsection{Total Output}

Regarding total output, hiring subsidies and job intermediation services for large firms have the greatest impact in aiding the recovery, followed by subsidies for the creation of small firms (that is, hiring subsidies for micro firms). Interestingly, hiring subsidies and job in- 
termediation subsidies for small businesses induce an improved near-term recovery in total output, but thereafter the recovery is dampened and the path of total output falls below that of the no-policy case. In the case of subsidies for the creation of micro firms, total output is always below the path of output in the no-policy case. In turn, for all purposes wage subsidies have no impact on the recovery of total output. ${ }^{17}$

While the magnitude of adjustment is different, the impact of policies on total output reflects the fact that, intuitively, policies that are directed toward the relatively more productive and capital intensive firms, that is, large firms, will tend to have a greater impact in aiding economic recoveries. Hiring subsidies and job intermediation subsidies for large firms decrease hiring costs for these firms (the latter by increasing large firms' job-filling probability, which drives down the expected cost of posting vacancies). As a result, employment is reallocated to large firms and, consequently, capital usage by large firms and investment will adjust accordingly (see the Appendix). All told, the recovery in total output is boosted as production is reallocated to the relatively more productive large-firm sector. Importantly, the capital allocation decision by large firms in response to the policy implies a smaller contraction in investment, which, coupled with the added incentive to hire workers from the policy, bolsters the recovery in large-firm output and total output. ${ }^{18}$ In turn, hiring subsidies and job intermediation for small firms aid the recovery in the near term, but as employment and capital is reallocated to the relatively less productive small-firm sector the recovery in total output eventually falls behind the no-policy case.

\footnotetext{
${ }^{17}$ The Appendix elaborates in greater detail on the underlying dynamics that drive the main results by showing impulse responses for several other variables, including large- and small-firm wages, self-employment earnings, investment, and capital usage by large firms. The Appendix also includes a summary of the results from a series of robustness checks, including different financing alternatives for subsidies and different parameterizations of the model. The main results of the paper are robust to these and other alternative experiments, assumptions, and calibrations, all of which are discussed in more detail in the Appendix.

${ }^{18}$ The quantitative impact on total output of job intermediation subsidies for large firms is greater than that of hiring subsidies for similar firms because, although both subsidies provide an incentive for vacancy posting, the job intermediation subsidy gives a boost to the large-firm job-filling probability by increasing matching efficiency as well, which amplifies the results. The opposite is true when we consider the same policies for existing small salaried firms. There are several reasons for this. First, due to the influence of sectoral market tightness on wages, the latter fall by less with an improvement in small-firm job intermediation services relative to the case with hiring subsidies. This effect, in turn, boosts small-firm vacancy posting by less. Second, better intermediation between the unemployed and small firms implies that the value of having a worker in an existing small firm falls by less (again, relative to the case with hiring subsidies). This limits the contraction in small firm owners, which in turn reduces the volatility of vacancy postings by existing small firms.
} 
In the case of subsidies for the creation of small firms, that is, hiring subsidies for micro firms, this policy also induces employment and capital usage reallocation to micro and small firms. However, in this case the magnitude of this reallocation is greater because of two forces: 1) existing micro firms take advantage of the subsidy, which increases the flows from self-employment status to small firm owner; 2) all else equal the value of self-employment is higher, which boosts capital-search expenditures and ultimately the inflow of individuals into self-employment status. Jointly, the extent to which these two forces reallocate production to less productive sectors leaves the recovery of total output only a touch improved relative to the no-policy case.

In the case of a subsidy for the creation of micro (self-employed) firms (that is, a capitalsearch expenditure subsidy), only force (2) from above is at play, which, all else equal, reduces capital usage among large firms and increases the supply of capital to the relatively less productive sector but does not yield significant salaried employment gains. Consequently, in this case the recovery in total output is subdued and lies beneath that of the no-policy case. ${ }^{19}$ Importantly, these results take place within a context where the reallocation of capital to the self-employed and small firm sectors relative to the total amount of capital in the economy is not very large. Yet, the policies generate important differences in the recovery process despite the relatively low usage of capital among micro and small firms. Wage subsidies will, all else equal, increase firm profits. Or, in the case of a recession, prevent profits from falling as much as they would otherwise. However, as shown in Figure 1 the fiscal package under consideration is insufficient to induce an impact on profits substantial enough to trigger mechanisms that affect the behavior of total output in any discernible way. ${ }^{20}$

\footnotetext{
${ }^{19}$ A caveat regarding hiring subsidies for self-employed individuals: the model assumes that self-employed individuals are homogeneous, and the only requirement to become a small firm is to successfully match with salaried workers via vacancy posting. However, in the data, the self-employed that expand tend to be those who are more successful and have higher ability and skills, which would translate into higher productivity. The model in its current form implicitly assumes that those who expand automatically inherit higher productivity. If we were to differentiate between high and low-ability entrepreneurs and use targeted subsidies for those with high ability (or the most potential), the quantitative impact of hiring subsidies for the self-employed would likely be smaller since only a very small fraction of the self-employed would benefit from the subsidy (those with higher ability). As such, our results represent an upper bound of the impact of these subsidies on aggregate dynamics.

${ }^{20}$ From a practical standpoint, wage subsidies for small firms may be hard to implement since these generally operate via temporary changes in payroll taxation, and as argued previously, obtaining revenue for these subsidies from these same firms during expansions is not trivial when a large proportion of small firms operates in the informal sector and hence does not face payroll taxes. Assuming that only a fraction
} 


\subsubsection{Consumption, Unemployment, and Wages}

Inspection of Figure 1 also shows that, intuitively, the behavior of consumption is largely in line with that of total output. One exception is the path of consumption in the case of subsidies for the creation of self-employed (micro) firms. Under this policy, on impact consumption contracts considerably below the no-policy case. Intuitively, this takes place because a subsidy for the creation of micro firms induces households to increase the resources devoted to capital search at the expense of the resources for consumption. ${ }^{21}$

Turning to unemployment, Figure 1 highlights that to greater or lesser degree all policies mute the increase in unemployment, with hiring subsidies for small firms and job intermediation services for both small and large firms even inducing a decline in unemployment. This is due to the strong response of sectoral vacancies to each of the policies. The only exception is the case of wage subsidies for large firms, which actually exacerbate the rise in unemployment. This policy keeps wages in large firms from declining as much as they would otherwise, which puts upward pressure on small-firm wages as workers' outside options remain higher than otherwise. Consequently, all else equal small-firm profits fall by more than otherwise, sharply reducing these firms' vacancy posting incentives. Thus, a greater decline in small-firm employment takes place, which explains the fact that unemployment initially rises more than in the no-policy case.

As shown in Figure 2, when looking at the average wage in the economy (that is, employment-weighted large-firm and small-firm wages), all subsidies tend to provide some degree of income protection for salaried workers, with the exception of job intermediation services for small businesses and subsidies for the creation of micro firms (see the Appendix for the behavior of wages by type of firm, as well as the behavior of self-employment earnings). Job intermediation for large firms has the greatest beneficial impact on income protection. Wage subsidies will naturally provide income protection. In other cases, the response of the average wage is heavily influenced by the response of unemployment, or, equivalently, the response of employment. Intuitively, a greater damping in the rise of unemployment is

of small firms benefit from the subsidy (those that are formal), or assuming that the subsidy is financed via an increase in the payroll tax for large firms (see the Appendix), yields qualitatively similar results, with the benefits from small-firm wage subsidies under these two scenarios being more subdued.

${ }^{21}$ A similar comment applies to the behavior of investment, shown in the Appendix. 
associated with higher measures of market tightness. In turn, higher measures of market tightness keep workers' outside options higher than otherwise and put upward pressure on the average wage. Thus, the magnitude of labor income adjustments (and hence income protection) is ultimately driven by the quantitative impact of each policy on sectoral market tightness.

\subsubsection{Fiscal Implications}

Inspection of Figure 2 also highlights that although the assumed size of the fiscal package in the period of the shock is 0.2 percent of output, the total fiscal cost can differ across policies. These differences arise because policies affect the recovery speed of output differently and they remain in place as long as output is below trend. While the fiscal cost in the first few periods after the shock is lower when hiring subsidies for small firms are in place, the fiscal cost of the policy falls back more rapidly with hiring subsidies for larger firms, job intermediation for large firms, and hiring subsidies for the self-employed (that is, small-firm creation subsidies). In addition, note that for the same size of the fiscal package, small and self-employed firms require larger hiring subsidy rates relative to those for large firms. Indeed, the subsidy rates for large firms do not have to be high to have an important quantitative impact on aggregate dynamics. Similarly, wage subsidy rates for both small and large firms end up being very small, below 1 percent on impact, which partly explains their limited impact on the recovery process.

To provide a better metric of the effectiveness of each of the policies considered, we follow the literature and compute cumulative multipliers for employment and output after a negative aggregate shock in the following way (see, for example, Faia, Lechthaler, and Merkl (2013)):

$$
M_{d}(p)=\frac{\sum_{i=0}^{d} \beta^{i}\left(x_{t+i}(p)-x_{t+i}\right)}{\sum_{i=0}^{d} \beta^{i}\left(f c_{t+i}(p)\right)},
$$

where $d$ is the number of quarters after the shock and $p$ is the policy for which the fiscal multiplier is computed. $x(p)$ is either total output, $y$, or total employment, $n$, under policy $p$, whereas $x$ represents either of these two variables under the no-policy scenario. $f c(p)$ is 
the fiscal cost of policy $p$, where the fiscal cost under the no-policy scenario is zero.

As shown in Table 10, small firm creation and self-employed firm creation policies are not particularly effective in bolstering output or employment. Hiring subsidies for existing small firms yield output and employment multipliers higher than 1 in the first year, which subsequently fall below 1 after three years. Focusing on employment, the fiscal multiplier is fairly stable in the medium run. Conversely, the output multiplier falls below 1 after three years. While hiring subsidies for large firms appear to be less effective in the first year, the output multiplier rises above 1 in the medium run because the policy induces a faster recovery in total output, but the latter takes some time to materialize. However, the employment multiplier remains below 1.

Table 10:

Cumulative Multipliers During Recessions

\begin{tabular}{cccc}
\hline \hline & \multicolumn{3}{c}{ Output Multipliers } \\
\cline { 2 - 4 } Policy $p$ & Quarters $d=4$ & Quarters $d=12$ & Quarters $d=30$ \\
\hline$\tau^{v_{L}}$ & 0.710 & 1.214 & 1.684 \\
$\tau^{v_{S B}}$ & 1.204 & 0.976 & 0.383 \\
$\tau^{v_{S E}}$ & -0.056 & 0.148 & 0.465 \\
$\tau^{k}$ & -0.155 & -0.325 & -0.520 \\
$\tau^{m_{L}}$ & 1.494 & 2.628 & 3.727 \\
$\tau^{m_{S B}}$ & 0.594 & 0.455 & 0.096 \\
$\tau^{w_{L}}$ & 0.091 & 0.198 & 0.320 \\
$\tau^{w_{S B}}$ & 0.242 & 0.218 & 0.129 \\
\cline { 2 - 3 } & \multicolumn{3}{c}{ Employment Multipliers } \\
\cline { 2 - 4 } Policy $p$ & Quarters $d=4$ & Quarters $d=12$ & Quarters $d=30$ \\
\hline$\tau^{v_{L}}$ & 0.310 & 0.521 & 0.681 \\
$\tau^{v_{S B}}$ & 1.284 & 1.403 & 1.308 \\
$\tau^{v_{S E}}$ & 0.256 & 0.291 & 0.288 \\
$\tau^{k}$ & 0.062 & 0.058 & 0.032 \\
$\tau^{m_{L}}$ & 0.611 & 1.048 & 1.388 \\
$\tau^{m_{S B}}$ & 0.642 & 0.705 & 0.648 \\
$\tau^{w_{L}}$ & -0.093 & -0.080 & -0.051 \\
$\tau^{w_{S B}}$ & 0.126 & 0.127 & 0.103 \\
\hline \multicolumn{3}{c}{}
\end{tabular}

Finally, the output multiplier generated by job intermediation services among large firms suggests that this policy is particularly effective in fostering a faster output recovery, even at short horizons. If we consider the medium term, this policy delivers an employment multiplier above 1 as well. These last two results suggest that improvements in job intermediation for employment among large firms is the most effective policy tool, followed by hiring subsidies for large firms and existing small firms. Wage subsidies yield very small (or even negative) 
output and employment multipliers and appear to be the least effective out of the set of policies considered.

\section{Conclusions}

The global financial crisis rekindled considerable interest in labor market policies that can lessen the employment and output costs of recessions. A number of recent studies have analyzed the impact of various employment subsidies for the United States. However, little work has focused on emerging and developing economies, where the breadth of self-employment and the large allocation of salaried employment in small firms implies non-trivial differences relative to advanced economies in the labor-market and firm structure. Understanding the aggregate implications of labor market structures and policies in emerging and developing economies is increasingly important given the dramatic rise in international linkages and cross-country spillovers that have occurred over the last several decades.

Data limitations on high-frequency labor and job flows in emerging and developing economies makes it difficult to assess empirically the effectiveness of any one countercylical policy. Furthermore, any empirical analysis will likely miss the general equilibrium effects of policy interventions. In order to get around these limitations, we use evidence on Latin America and build a business cycle model with frictional labor markets consistent with the salient features of the firm and employment structure of emerging and developing economies. In turn, we use the model to analyze the aggregate impact of different cyclical labor market policies during downturns.

We show that the model is consistent with the cyclical dynamics of the labor market in a representative emerging economy. With regards to policy, we obtain four main results. First, hiring subsidies for large firms and improved intermediation between large firms and the unemployed during downturns can yield gains across the board: a reduction in aggregate volatility, an acceleration in the rebound of total output and consumption, a smaller contraction in labor earnings, a lower rise in unemployment, lower unemployment persistence after a recession, and employment and output fiscal multipliers above 1 in the medium term. Second, hiring subsidies for small firms can yield non-negligible positive results for employment - in 
particular, employment among small salaried firms - but these effects are short-lived and the policy slows down the recovery process in the medium term. Third, fostering the creation of self-employed firms during downturns can be detrimental for the recovery process and the economy as a whole, even as these firms may ultimately lead to future salaried employment creation. This last result is particularly important in light of the policies that many emerging countries implemented to support the creation of micro and small enterprises. Fourth, wage subsidies are relatively ineffective in bolstering output when compared to other alternatives, but do provide some income protection. Model-implied fiscal multipliers suggest that hiring subsidies and job intermediation for large firms are particularly effective in aiding recoveries. The labor market structure determines the sectoral allocation of resources and explains the differential response of the economy to policy.

Our model provides the basis for several interesting extensions. These include accounting for the implications of entry dynamics among larger firms, worker and consumption heterogeneity, as well as the difference between low and high-ability self-employed, and job-to-job transitions. Moreover, while the model is consistent with existing evidence on the continued use of informal input credit among small firms, studying the implications of financial development is important as it may lead to a change in the availability of financing sources and the productivity profile of firms. Such changes could, in turn, modify the effectiveness of cyclical policies aimed at protecting employment and improving recoveries in emerging economies. We plan to explore these extensions in future work.

\section{References}

[1] Adjemian, Stéphane, Houtan Bastani, Michel Juillard, Ferhat Mihoubi, George Perendia, Marco Ratto and Sébastien Villemot. 2011. "Dynare: Reference Manual, Version 4," Dynare Working Papers, 1, CEPREMAP.

[2] Arseneau, David M. and Brendan Epstein. 2014. "The Welfare Costs of Skill-Mismatch Employment." Finance and Economics Discussion Series 2014-42, Board of Governors of the Federal Reserve System. 
[3] Banerji, Arup, David Newhouse, Pierella Paci, and David Robalino. 2014. "Working Through the Crisis: Jobs and Policies in Developing Countries during the Great Recession," The World Bank Group: Washington D.C.

[4] Bosch, Mariano and Willam Maloney. 2008. "Cyclical Movements in Unemployment and Informality in Developing Countries," mimeo.

[5] Boz, Emine, Ceyhun Bora Durdu, and Nan Li. 2012. "Emerging Market Business Cycles: The Role of Labor Market Frictions," IMF Working Papers 12/23\%.

[6] Busso, Matías, María Victoria Fazio, and Santiago Levy. 2012. "(In)formal and (Un)productive: The Productivity Costs of Excessive Informality in Mexico," IDB Working Paper Series No. IDB-WP-341.

[7] Busso, Matías, Lucía Madrigal, and Carmen Pagés. 2012. "Productivity and Resource Misallocation in Latin America," IDB Working Paper Series No. IDB-WP-306.

[8] Campolmi, Alessia, Ester Faia, and Roland C. Winkler. 2011. "Fiscal Calculus and the Labor Market," B.E. Journal of Macroeconomics, Vol. 11, Issue 1, Article 38, pp. 1-25.

[9] Canzoneri, Matthew, Fabrice Collard, Harris Dellas, and Behzad Diba. 2011. "Fiscal Multipliers in Recessions," mimeo.

[10] Epstein, Brendan. 2012. "Heterogeneous Workers, Optimal Job Seeking, and Aggregate Labor Market Dynamics." International Finance Discussion Papers 1053, Board of Governors of the Federal Reserve System.

[11] Faia, Ester, Wolfgang Lechthaler, and Christian Merkl. "Fiscal Stimulus and Labor Market Policies in Europe," Journal of Economic Dynamics and Control, Vol. 37, pp. 483-499.

[12] Farazi, Subika. 2014. "Informal Firms and Financial Inclusion: Status and Determinants," World Bank Policy Research Working Paper No. WPS 6778.

[13] Fernández, Andrés, and Felipe Meza. 2014. "Labor Informality and Business Cycles in Emerging Economies," Review of Economic Dynamics, forthcoming.

[14] Finkelstein Shapiro, Alan. 2014. "Self-Employment and Business Cycle Persistence: Does the Composition of Employment Matter for Economic Recoveries?" Journal of Economic Dynamics and Control, Vol. 46, September 2014, pp. 200-218. 
[15] Global Financial Development Report. 2014. "Financial Inclusion," The World Bank Group: Washington D.C.

[16] Hosios, Arthur J. (1990). "On the Efficiency of Matching and Related Models of Search and Unemployment." Review of Economic Studies, 57(2), 279-298.

[17] IDB. 2005a. "Unlocking Credit, The Quest for Deep and Stable Bank Lending," Research Department, Inter-American Development Bank: Washington D.C. http://www.iadb.org/res/ipes/2005/index.cfm.

[18] IDB. 2005b. "Developing Entrepreneurship: Experience in Latin America and Worldwide," Edited by Hugo Kantis, with collaboration of Pablo Angelelli and Virginia Moori Koenig, Inter-American Development Bank: Washington D.C. http://idbdocs.iadb.org/wsdocs/getdocument.aspx?docnum=834797.

[19] ILO. 2011. "A Review of Global Fiscal Stimulus," EC-IILS Joint Discussion Paper Series No. 5.

[20] ILO and World Bank. 2012. "Inventory of Policy Responses to the Financial and Economic Crisis," ILO/World Bank Joint Synthesis Report. The World Bank Group: Washington D.C.

[21] Kantis, Hugo, Masahiko Ishida, and Masahiko Komori. 2002. "Entrepreneurship in Emerging Economies: The Creation and Development of New Firms in Latin America and East Asia," Inter-American Development Bank: Washington D.C.

[22] Kitao, Sagiri, Ayşegül Şahin, and Joseph Song. 2010. "Subsidizing Job Creation in the Great Recession," Federal Reserve Bank of New York Staff Report No. 451.

[23] Kurmann, Andre, and Nicolas Petrosky-Nadeau. 2007. "Search Frictions in Physical Capital Markets as a Propagation Mechanism," Working Paper 0\%-12, Centre Interuniversitaire sur le Risque, les Politiques Economiques et l'Emploi.

[24] Lee, Yoonsoo, and Toshihiko Mukoyama. 2013. "Entry, Exit, and Plant-Level Dynamics Over the Business Cycle," mimeo.

[25] Levy, Santiago. 2007. "Can Social Programs Reduce Productivity and Growth? A Hypothesis for Mexico," IPC Working Paper Series Number 37, Gerald R. Ford School of Public Policy, University of Michigan. 
[26] Loayza, Norman, and Jamele Rigolini. 2011. "Informal Employment: Safety Net or Growth Engine?" World Development, Vol. 39, Issue 9, pp. 1503-1515.

[27] McKenzie, David J., and Christopher Woodruff. 2006. "Do Entry Costs Provide an Empirical Basis for Poverty Traps? Evidence from Mexican Microenterprises," Economic Development and Cultural Change, Vol. 55,No. 1, pp. 3-42.

[28] Nicoletti, Giulio, and Olivier Pierrard. 2006. "Capital Market Frictions and the Business Cycle," Discussion Paper 2006-53, Département des Sciences Économiques de l'Université Catholique de Louvain.

[29] Perry, Guillermo E., William F. Maloney, Omar S. Arias, Pablo Fajnzylber, Andrew D. Mason, and Jaime Saavedra-Chanduvi. 2007. "Informality: Exit and Exclusion," The World Bank Group: Washington D.C.

[30] Sedláček, Petr. 2011. "Firm Age, Business Cycles, and Aggregate Labor Market Dynamics," mimeo.

[31] Sedláček, Petr, and Vincent Sterk. 2013. "Recession Scars and the Growth Potential of Newborn Firms in General Equilibrium," mimeo.

[32] Shao, Enchuan, and Pedro Silos. 2008. "Firm Entry and Labor Market Dynamics," Federal Reserve Bank of Atlanta Working Paper 2008-17.

[33] Shimer, Robert. 2005. "The Cyclical Behavior of Equilibrium Unemployment and Vacancies." American Economic Review, Vol. 95(1), pp. 25-49.

[34] Siemer, Michael. 2013. "Firm Entry and Employment Dynamics in the Great Recession," mimeo.

[35] Totzek, Alexander, and Roland C. Winkler. 2010. "Fiscal Stimulus in a Business Cycle Model with Firm Entry," mimeo.

\section{A Appendix}

\section{A.1 Household Optimization}

Assigning the multipliers $\Lambda_{t}, \Lambda_{K, t}, \Lambda_{O S B, t}$ and $\Lambda_{N S B, t}$ to the household's budget constraint, the household's perceived law of motion for self-employment, its perceived law of motion for 
small business owners, and its perceived (from the labor demand perspective) law of motion for employment in small firms, respectively, the corresponding first order conditions are as follows. For consumption $c_{t}$,

$$
u^{\prime}\left(c_{t}\right)-\Lambda_{t}=0
$$

For self-employed individuals, $n_{S E, t+1}$,

$$
\begin{gathered}
\beta \mathbb{E}_{t} \Lambda_{t+1}\left[\left(p_{S E, t+1} z_{S E, t+1}-r_{S E, t+1}\right)-\tau_{t+1}^{v_{S E}} \psi_{S E} v_{S E, t+1}\right] \\
+\beta\left(1-\rho_{t+1}^{K}\right) \mathbb{E}_{t}\left[\left(1-\left(1-\rho_{t+1}^{O}\right)\left(1-\rho_{t+1}^{S}\right) v_{S E, t+1} q\left(\theta_{S E, t+1}\right)\right) \Lambda_{K, t+1}\right. \\
\left.+\left(1-\rho_{t+1}^{O}\right)\left(1-\rho_{t+1}^{S}\right) v_{S E, t+1} q\left(\theta_{S E, t+1}\right) \Lambda_{O S B, t+1}\right] \\
+\beta\left(1-\rho_{t+1}^{K}\right)\left(1-\rho_{t+1}^{O}\right)\left(1-\rho_{t+1}^{S}\right) \mathbb{E}_{t} v_{S E, t+1} q\left(\theta_{S E, t+1}\right) \Lambda_{N S B, t+1}^{d}-\Lambda_{K, t}=0 .
\end{gathered}
$$

For self-employment projects, $s_{K, t}$ :

$$
-\Lambda_{t} \tau_{t}^{\kappa} \kappa^{\prime}\left(s_{K, t}\right)+\left(1-\rho_{t}^{K}\right) p\left(\theta_{K, t}\right) \Lambda_{K, t}=0
$$

For small business owners, $o_{S B, t+1}$ :

$$
\begin{gathered}
\beta \mathbb{E}_{t} \Lambda_{t+1}\left[p_{S B, t+1} z_{S B, t+1} F_{o_{S B, t+1}^{h}}\left(n_{S B, t+1}, o_{S B, t+1}\right)-r_{S B, t+1}-\tau_{t+1}^{v_{S B}} \psi_{S B} v_{S B, t+1}\right] \\
+\beta\left(1-\rho_{t+1}^{K}\right) \rho_{t+1}^{O} \mathbb{E}_{t} \Lambda_{K, t+1} \\
+\beta\left(1-\rho_{t+1}^{K}\right)\left(1-\rho_{t+1}^{O}\right) \mathbb{E}_{t} \Lambda_{O S B, t+1} \\
+\beta\left(1-\rho_{t+1}^{K}\right)\left(1-\rho_{t+1}^{O}\right)\left(1-\rho_{t+1}^{S}\right) \mathbb{E}_{t} \Lambda_{N S B, t+1} v_{S B, t+1} q\left(\theta_{S B, t+1}\right)-\Lambda_{O S B, t}=0
\end{gathered}
$$

The demand for individuals employed by small businesses, $n_{S B, t+1}^{d}$ :

$$
\begin{aligned}
& \beta \mathbb{E}_{t} \Lambda_{t+1}\left[p_{S B, t+1} z_{S B, t+1} F_{n_{S B, t+1}^{d}}\left(n_{S B, t+1}, o_{S B, t+1}\right)-\tau_{t+1}^{w_{S B}} w_{S B, t+1}\right] \\
& +\beta\left(1-\rho_{t+1}^{K}\right)\left(1-\rho_{t+1}^{O}\right)\left(1-\rho_{t+1}^{S}\right) \mathbb{E}_{t} \Lambda_{N S B, t+1}-\Lambda_{N S B, t}=0
\end{aligned}
$$


Vacancies posted per self-employed individual, $v_{S E, t}$ :

$$
\begin{aligned}
& -\Lambda_{t} \tau_{t}^{v_{S E}} \psi_{S E}-\Lambda_{K, t}\left(1-\rho_{t}^{K}\right)\left(1-\rho_{t}^{O}\right)\left(1-\rho_{t}^{S}\right) q\left(\theta_{S E, t}\right) \\
& +\Lambda_{O S B, t}\left(1-\rho_{t}^{K}\right)\left(1-\rho_{t}^{O}\right)\left(1-\rho_{t}^{S}\right) q\left(\theta_{S E, t}\right) \\
& +\left(1-\rho_{t}^{K}\right)\left(1-\rho_{t}^{O}\right)\left(1-\rho_{t}^{S}\right) q\left(\theta_{S E, t}\right) \Lambda_{N S B, t}=0 .
\end{aligned}
$$

And vacancies posted per small business, $v_{S B, t}$ :

$$
-\Lambda_{t} \tau_{t}^{v_{S B}} \psi_{S B}+\left(1-\rho_{t}^{K}\right)\left(1-\rho_{t}^{O}\right)\left(1-\rho_{t}^{S}\right) q\left(\theta_{S B, t}\right) \Lambda_{N S B, t}=0
$$

From the first-order condition for consumption, we know that

$$
\Lambda_{t}=u^{\prime}\left(c_{t}\right)
$$

Then, we can write

$$
\frac{\Lambda_{K, t}}{u^{\prime}\left(c_{t}\right)}=\frac{\tau_{t}^{\kappa} \kappa^{\prime}\left(s_{K, t}\right)}{\left(1-\rho_{t}^{K}\right) p\left(\theta_{K, t}\right)}
$$

and obtain

$$
\frac{\Lambda_{N S B, t}}{u^{\prime}\left(c_{t}\right)}=\frac{\tau_{t}^{v_{S B}} \psi_{S B}}{\left(1-\rho_{t}^{K}\right)\left(1-\rho_{t}^{O}\right)\left(1-\rho_{t}^{S}\right) q\left(\theta_{S B, t}\right)} .
$$

Also, we have

$$
\left(1-\rho_{t}^{K}\right)\left(1-\rho_{t}^{O}\right)\left(1-\rho_{t}^{S}\right) \frac{\Lambda_{O S B, t}}{u^{\prime}\left(c_{t}\right)}=\frac{\tau_{t}^{v_{S E}} \psi_{S E}}{q\left(\theta_{S E, t}\right)}-\frac{\tau_{t}^{v_{S B}} \psi_{S B}}{q\left(\theta_{S B, t}\right)}+\frac{\tau_{t}^{\kappa} \kappa^{\prime}\left(s_{K, t}\right)}{p\left(\theta_{K, t}\right)}
$$

To determine the optimal decision to become a small firm, we write:

$$
\begin{gathered}
\frac{\Lambda_{O S B, t}}{\Lambda_{t}}=\mathbb{E}_{t} \beta \frac{\Lambda_{t+1}}{\Lambda_{t}}\left\{p_{S B, t+1} z_{S B, t+1} F_{O_{S B}}\left(n_{S B, t+1}, o_{S B, t+1}\right)\right. \\
-r_{S B, t+1}-\tau_{t}^{v_{S B}} \psi_{S B} v_{S B, t+1}+\left(1-\rho^{K}\right) \rho^{O} \frac{\Lambda_{K, t+1}}{\Lambda_{t+1}} \\
+\left(1-\rho_{t+1}^{K}\right)\left(1-\rho_{t+1}^{O}\right)\left(1-\rho_{t+1}^{S}\right) \frac{\Lambda_{N S B, t+1}}{\Lambda_{t+1}} v_{S B, t+1} q\left(\theta_{S B, t+1}\right) \\
\left.+\left(1-\rho_{t+1}^{K}\right)\left(1-\rho_{t+1}^{O}\right) \frac{\Lambda_{O S B, t+1}}{\Lambda_{t+1}}\right\} .
\end{gathered}
$$


Then, use the expressions above as well as the optimal decision to move into self-employment to yield (iterating forward when necessary):

$$
\begin{array}{r}
\frac{1}{\left(1-\rho_{t}^{S}\right)\left(1-\rho_{t}^{K}\right)\left(1-\rho_{t}^{O}\right)}\left(\frac{\tau_{t}^{v_{S E}} \psi_{S E}}{q_{S E, t}}-\frac{\tau_{t}^{v_{S B}} \psi_{S B}}{q_{S B, t}}\right) \\
=\mathbb{E}_{t} \Xi_{t+1 \mid t}\left\{\begin{array}{c}
p_{S B, t+1} z_{S B, t+1} F_{o_{S B}}\left(n_{S B, t+1}, o_{S B, t+1}\right) \\
-r_{S B, t+1}-\left(p_{S E, t+1} z_{S E, t+1}-r_{S E, t+1}\right) \\
+\frac{1}{\left(1-\rho_{t+1}^{S}\right)}\left(\frac{\tau_{t+1}^{v_{S E}} \psi_{S E}}{q_{S E, t+1}}-\frac{\tau_{t+1}^{v_{S B}} \psi_{S B}}{q_{S B, t+1}}\right)
\end{array}\right\} .
\end{array}
$$

where: $\Xi_{t+1 \mid t}=\beta u_{t+1}^{\prime} / u_{t}^{\prime}$ is the stochastic discount factor. This equation implicitly defines $v_{S E, t}$.

To derive the decision to enter self-employment, first write:

$$
\begin{aligned}
& \frac{\Lambda_{K, t}}{\Lambda_{t}}=\mathbb{E}_{t} \beta \frac{\Lambda_{t+1}}{\Lambda_{t}}\left\{\left(p_{S E, t+1} z_{S E, t+1}-r_{S E, t+1}\right)-\tau_{t+1}^{v_{S E}} \psi_{S E} v_{S E, t+1}\right. \\
& +\left(1-\rho_{t+1}^{K}\right)\left(1-\left(1-\rho_{t+1}^{O}\right)\left(1-\rho_{t+1}^{S}\right) v_{S E, t+1} q\left(\theta_{S E, t+1}\right)\right) \frac{\Lambda_{K, t+1}}{\Lambda_{t+1}} \\
& \quad+\left(1-\rho_{t+1}^{K}\right)\left(1-\rho_{t+1}^{O}\right)\left(1-\rho_{t+1}^{S}\right) v_{S E, t+1} q\left(\theta_{S E, t+1}\right) \frac{\Lambda_{O S B, t+1}}{\Lambda_{t+1}} \\
& \left.\quad+\left(1-\rho_{t+1}^{K}\right)\left(1-\rho_{t+1}^{O}\right)\left(1-\rho_{t+1}^{S}\right) v_{S E, t+1} q\left(\theta_{S E, t+1}\right) \frac{\Lambda_{N S B, t+1}}{\Lambda_{t+1}}\right\} .
\end{aligned}
$$

Using the equations above, we can rewrite the above expression to have:

$$
\frac{\tau_{t}^{\kappa} \kappa^{\prime}\left(s_{K, t}\right)}{p\left(\theta_{K, t}\right)}=\left(1-\rho_{t}^{K}\right) \mathbb{E}_{t} \Xi_{t+1 \mid t}\left\{p_{S E, t+1} z_{S E, t+1}-r_{S E, t+1}+\frac{\tau_{t+1}^{\kappa} \kappa^{\prime}\left(s_{K, t}\right)}{p\left(\theta_{K, t+1}\right)}\right\}
$$

This equation implicitly defines $s_{K, t}$.

\section{A.2 Value Equations and Nash Price Determination}

\section{A.2.1 Value Equations}

In what follows, we define the household and firm value functions to determine the Nash wage and rental rates. The value of having an additional salaried worker in a large firm, $\mathbf{J}_{L, t}$, is given by the difference between the firm's marginal revenue product of labor and the subsidy-adjusted wage, plus the continuation value in the event that the match survives 
into the following period (in equilibrium the value of any vacancy is zero - this reflects that vacancies are posted until the value of doing so is exhausted):

$$
\mathbf{J}_{L, t}=p_{L, t} z_{L, t} \mathbb{F}_{n_{L}}\left(n_{L, t}, \omega_{t} k_{L, t}\right)-\tau_{t}^{w_{L}} w_{L, t}+\left(1-\rho_{t}^{L}\right) \mathbb{E}_{t} \Xi_{t+1 \mid t} \mathbf{J}_{L, t+1}
$$

Similar intuition lies behind the value of an additional salaried worker for a small business, $\mathbf{J}_{S B, t}$ :

$$
\begin{gathered}
\mathbf{J}_{O S B, t}=p_{S B, t} z_{S B, t} F_{n_{S B}}\left(n_{S B, t}, o_{S B, t}\right)-\tau_{t}^{w_{S B}} w_{S B, t} \\
+\mathbb{E}_{t} \Xi_{t+1 \mid t}\left\{\left(1-\rho_{t}^{K}\right)\left(1-\rho_{t}^{O}\right)\left(1-\rho_{t}^{S}\right) \mathbf{J}_{O S B, t+1}\right\} .
\end{gathered}
$$

The household's value of having an additional individual in salaried employment in a large firm, $\mathbf{W}_{L, t}$, is given by corresponding wage payment plus the expected continuation value:

$$
\mathbf{W}_{L, t}=w_{L, t}+\mathbb{E}_{t} \Xi_{t+1 \mid t}\left\{\left(1-\rho_{t}^{L}\right) \mathbf{W}_{L, t+1}+\rho_{t}^{L} \mathbf{W}_{U, t+1}\right\}
$$

where: $\mathbf{W}_{U}$ is the household's value of unemployment. Similar intuition lies behind the value of having an additional household member employed by a small business $\mathbf{W}_{S B, t}$ :

$$
\mathbf{W}_{S B, t}=w_{S B, t}+E_{t} \Xi_{t+1 \mid t}\left\{\begin{array}{c}
\left(1-\rho_{t}^{K}\right)\left(1-\rho_{t}^{O}\right)\left(1-\rho_{t}^{S}\right) \mathbf{W}_{S B, t+1} \\
+\left[1-\left(1-\rho_{t}^{K}\right)\left(1-\rho_{t}^{O}\right)\left(1-\rho_{t}^{S}\right)\right] \mathbf{W}_{U, t+1}
\end{array}\right\}
$$

In turn, the household's value of unemployment is:

$$
\mathbf{W}_{U, t}=b+\mathbb{E}_{t} \Xi_{t+1 \mid t}\left\{\begin{array}{c}
\left(1-\rho_{t}^{L}\right) p\left(\theta_{L, t}\right) \mathbf{W}_{L, t+1}+\left(1-\rho_{t}^{K}\right) s_{K, t}^{u} f_{K, t} \mathbf{W}_{S E, t+1} \\
+\left(1-\rho_{t}^{K}\right)\left(1-\rho_{t}^{O}\right)\left(1-\rho_{t}^{S}\right)\left[f_{S B, t}+f_{S E, t}\right] \mathbf{W}_{S B, t+1} \\
+\left[\begin{array}{c}
1-\left(1-\rho_{t}^{L}\right) f_{L, t}-\left(1-\rho_{t}^{K}\right) s_{K, t}^{u} f_{K, t} \\
-\left(1-\rho_{t}^{K}\right)\left(1-\rho_{t}^{O}\right)\left(1-\rho_{t}^{S}\right)\left[f_{S B, t}+f_{S E, t}\right]
\end{array}\right] \mathbf{W}_{U, t+1}
\end{array}\right\},
$$

where: $\mathbf{W}_{S E, t}$ is the value to the household of an additional self-employed individual (defined below) and $s_{K, t}^{u}$ is the amount of resources spent on searching for a capital supplier per unemployed individual $\left(s_{K, t}^{u} \equiv s_{K, t} / u_{t}\right)$.

The value to a large firm of having a capital relationship with a self-employed individual, 
$\mathbf{J}_{S E, t}$, is given by the corresponding rental rate adjusted for the probability that the capital relationship is destroyed net of the capital depreciation rate plus the expected continuation value:

$$
\mathbf{J}_{S E, t}=r_{S E, t}+\left(\rho_{t}^{K}-\delta\right)+E_{t} \Xi_{t+1 \mid t}\left\{\begin{array}{c}
\left(1-\rho_{t}^{K}\right)\left(1-\left(1-\rho_{t}^{O}\right)\left(1-\rho_{t}^{S}\right) v_{S E, t} q_{S E, t}\right) \mathbf{J}_{S E, t+1} \\
+\left(1-\rho_{t}^{K}\right)\left(1-\rho_{t}^{O}\right)\left(1-\rho_{t}^{S}\right) v_{S E, t} q_{S E, t} \mathbf{J}_{S B, t+1}
\end{array}\right\} .
$$

Similar intuition lies behind the value to a large firm of having a capital relationship with a small business, $\mathbf{J}_{S B, t}$ :

$$
\mathbf{J}_{S B, t}=r_{S B, t}+\left[\left(1-\left(1-\rho_{t}^{O}\right)\left(1-\rho_{t}^{S}\right)-\delta\right]+E_{t} \Xi_{t+1 \mid t}\left\{\begin{array}{c}
\left(1-\rho_{t}^{K}\right)\left(1-\rho_{t}^{O}\right) \mathbf{J}_{S B, t+1} \\
+\left(1-\rho_{t}^{K}\right) \rho_{t}^{O} \mathbf{J}_{S E, t+1}
\end{array}\right\} .\right.
$$

In turn, the value to a self-employed individual of having a capital relationship with a large firm, $\mathbf{W}_{S E, t}$, is given by the difference between the marginal revenue product of capital and the rental rate, plus the expected continuation value:

$$
\begin{gathered}
\mathbf{W}_{S E, t}=p_{S E, t} z_{S E, t}-r_{S E, t} \\
+\mathbb{E}_{t} \Xi_{t+1 \mid t}\left\{\begin{array}{c}
\left(1-\rho_{t}^{K}\right)\left[1-\left(1-\rho_{t}^{O}\right)\left(1-\rho_{t}^{S}\right) v_{S E, t} q_{S E, t}\right] \mathbf{W}_{S E, t+1} \\
+\left(1-\rho_{t}^{K}\right)\left(1-\rho_{t}^{O}\right)\left(1-\rho_{t}^{S}\right) v_{S E, t} q_{S E, t} \mathbf{J}_{O S B, t+1}+\rho_{t}^{K} \mathbf{W}_{U, t+1}
\end{array}\right\} .
\end{gathered}
$$

Finally, similar intuition as before applies to the value to a household of having an additional capital relationship between a small firm and a large firm, $\mathbf{W}_{O S B, t}$, which is given by:

$$
\begin{gathered}
\mathbf{W}_{O S B, t}=p_{S B, t} z_{S B, t} F_{o S B}\left(n_{S B, t}^{d}, o_{S B, t}\right)-r_{S B, t} \\
+\mathbb{E}_{t} \Xi_{t+1 \mid t}\left\{\begin{array}{c}
\left(1-\rho_{t}^{K}\right)\left(1-\rho_{t}^{O}\right) \mathbf{W}_{O S B, t+1} \\
+\left(1-\rho_{t}^{K}\right) \rho_{t}^{O} \mathbf{W}_{S E, t+1}+\rho_{t}^{K} \mathbf{W}_{U, t+1}
\end{array}\right\} .
\end{gathered}
$$

\section{A.2.2 Nash Wage Rate Determination}

Large firms and salaried workers choose a wage $w_{L, t}$ to

$$
\max _{w_{L, t}}\left\{\left(\mathbf{W}_{L, t}-\mathbf{W}_{U, t}\right)^{\chi_{L}}\left(\mathbf{J}_{L, t}\right)^{1-\chi_{L}}\right\}
$$


Small business owners and small firm salaried workers choose a wage $w_{S B, t}$ to

$$
\max _{w_{S B, t}}\left\{\left(\mathbf{W}_{S B, t}-\mathbf{W}_{U, t}\right)^{\chi_{S B}}\left(\mathbf{J}_{O S B, t}\right)^{1-\chi_{S B}}\right\}
$$

Above $\chi_{L} \in(0,1)$ and $\chi_{S B} \in(0,1)$ are, respectively, the bargaining power of workers negotiating with large firms and the bargaining power of workers negotiating with small businesses. $\mathbf{W}_{L, t}-\mathbf{W}_{U, t}$ and $\mathbf{J}_{L, t}$ are the household's and large firm's respective capital gains from large firm salaried employment. Similarly, $\mathbf{W}_{S B, t}-\mathbf{W}_{U, t}$ and $\mathbf{J}_{O S B, t}$ are the household's and small business owner's capital gains from salaried employment in small firms. The implicit expressions for the Nash wages are given by

$$
\frac{\chi_{L}}{\left(1-\chi_{L}\right) \tau_{t}^{w_{L}}} \mathbf{J}_{L, t}=\left(\mathbf{W}_{L, t}-\mathbf{W}_{U, t}\right)
$$

for $w_{L, t}$ and

$$
\frac{\chi_{S B}}{\left(1-\chi_{S B}\right) \tau_{t}^{w_{S B}}} \mathbf{J}_{O S B, t}=\left(\mathbf{W}_{S B, t}-\mathbf{W}_{U, t}\right)
$$

for $w_{S B, t}$.

\section{A.2.3 Nash Rental Rate Determination}

Large firms and the self-employed choose a rental rate $r_{S E, t}$ to

$$
\max _{r_{S E, t}}\left\{\left(\mathbf{W}_{S E, t}-\mathbf{W}_{U, t}\right)^{\chi_{K}}\left(\mathbf{J}_{S E, t}-(1-\delta)\right)^{1-\chi_{K}}\right\}
$$

Large firms and small business owners choose a rental rate $r_{S B, t}$ to

$$
\max _{r_{S B, t}}\left\{\left(\mathbf{W}_{O S B, t}-\mathbf{W}_{U, t}\right)^{\chi_{O}}\left(\mathbf{J}_{S B, t}-(1-\delta)\right)^{1-\chi_{O}}\right\}
$$

Above, the outside option of large firms is the value of a unit of capital net of depreciation, $(1-\delta)$. Also, $\chi_{S E} \in(0,1)$ and $\chi_{O} \in(0,1)$ are, respectively, the bargaining power of selfemployed and small business owners. $\mathbf{W}_{S E, t}-\mathbf{W}_{U, t}$ and $\mathbf{J}_{S E, t}-(1-\delta)$ are the household's and large firm's respective capital gains from self-employment capital relationships. Similarly, $\mathbf{W}_{O S B, t}-\mathbf{W}_{U, t}$ and $\mathbf{J}_{S B, t}-(1-\delta)$ are the household's and the large firm's respective capital 
gains from small firm capital relationships. The implicit expressions for the Nash rental rates are given by

$$
\frac{\chi_{K}}{\left(1-\chi_{K}\right)}\left(\mathbf{J}_{S E, t}-(1-\delta)\right)=\left(\mathbf{W}_{S E, t}-\mathbf{W}_{U, t}\right)
$$

for $r_{S E, t}$ and

$$
\frac{\chi_{O}}{\left(1-\chi_{O}\right)}\left(\mathbf{J}_{S B, t}-(1-\delta)\right)=\left(\mathbf{W}_{O S B, t}-\mathbf{W}_{U, t}\right)
$$

for $r_{S B, t}$.

\section{A.2.4 Explicit Wage Expressions Without Policy}

To obtain explicit expressions for wages without the policies in place, first note that

$$
\begin{gathered}
\frac{\psi_{L}}{q_{L, t}}=\left(1-\rho_{t}^{L}\right) \mathbb{E}_{t} \Xi_{t+1 \mid t} \mathbf{J}_{L, t+1}, \\
\frac{p_{L, t} z_{L, t} \mathbb{F}_{\omega k_{L}}\left(n_{L, t}, \omega_{t} k_{L, t}\right)+\left(1-\rho_{t}^{K}\right) q_{K, t}}{q_{K, t}}=\left(1-\rho_{t}^{K}\right) \mathbb{E}_{t} \Xi_{t+1 \mid t} \mathbf{J}_{S E, t+1},
\end{gathered}
$$

and

$$
\frac{\psi_{S B}}{q_{S B, t}}=\left(1-\rho_{t}^{O}\right)\left(1-\rho_{t}^{S}\right)\left(1-\rho_{t}^{K}\right) \mathbb{E}_{t} \Xi_{t+1 \mid t} \mathbf{J}_{O S B, t+1} .
$$

Then, write

$$
\begin{gathered}
\mathbf{W}_{L, t}-\mathbf{W}_{U, t}=w_{L, t}+\mathbb{E}_{t} \Xi_{t+1 \mid t}\left\{\left(1-\rho_{t}^{L}\right) \mathbf{W}_{L, t+1}+\rho_{t}^{L} \mathbf{W}_{U, t+1}\right\}-b \\
+\mathbb{E}_{t} \Xi_{t+1 \mid t}\left\{\begin{array}{c}
\left(1-\rho_{t}^{L}\right) f_{L, t} \mathbf{W}_{L, t+1}+\left(1-\rho_{t}^{K}\right) s_{K, t}^{u} f_{K, t} \mathbf{W}_{S E, t+1} \\
+\left(1-\rho_{t}^{K}\right)\left(1-\rho_{t}^{O}\right)\left(1-\rho_{t}^{S}\right)\left(f_{S B, t}+f_{S E, t}\right) \mathbf{W}_{S B, t+1} \\
+\left[\begin{array}{c}
1-\left(1-\rho_{t}^{L}\right) p_{L t}-\left(1-\rho_{t}^{K}\right) s_{K, t}^{u} f_{K, t} \\
-\left(1-\rho_{t}^{K}\right)\left(1-\rho_{t}^{O}\right)\left(1-\rho_{t}^{S}\right)\left(f_{S B, t}+f_{S E, t}\right)
\end{array}\right] \mathbf{W}_{U, t+1}
\end{array}\right\},
\end{gathered}
$$

where $s_{K, t}^{u} \equiv s_{K, t} / u_{t}$. After some algebra, we have

$$
\begin{gathered}
\mathbf{W}_{L, t}-\mathbf{W}_{U, t}=w_{L, t}-b+\mathbb{E}_{t} \Xi_{t+1 \mid t}\left\{\left(1-\rho_{t}^{L}\right)\left(1-f_{L, t}\right)\left(\mathbf{W}_{L, t+1}-\mathbf{W}_{U, t+1}\right)\right\} \\
+\mathbb{E}_{t} \Xi_{t+1 \mid t}\left\{\begin{array}{c}
\left(1-\rho_{t}^{K}\right) s_{K, t}^{u} f_{K, t}\left(\mathbf{W}_{S E, t+1}-\mathbf{W}_{U, t+1}\right) \\
+\left(1-\rho_{t}^{K}\right)\left(1-\rho_{t}^{O}\right)\left(1-\rho_{t}^{S}\right)\left(f_{S B, t}+f_{S E, t}\right)\left(\mathbf{W}_{S B, t+1}-\mathbf{W}_{U, t+1}\right)
\end{array}\right\} .
\end{gathered}
$$


Using the first-order conditions that determine the implicit functions for $w_{L, t}, w_{S B, t}$, and $r_{S E, t}$, we can write

$$
\begin{gathered}
\frac{\chi_{L}}{\left(1-\chi_{L}\right)} \mathbf{J}_{L, t}=w_{L, t}-b+\mathbb{E}_{t} \Xi_{t+1 \mid t}\left\{\left(1-\rho_{t}^{L}\right)\left(1-f_{L, t}\right) \frac{\chi_{L}}{\left(1-\chi_{L}\right)} \mathbf{J}_{L, t+1}\right\} \\
+\mathbb{E}_{t} \Xi_{t+1 \mid t}\left\{\begin{array}{c}
\left(1-\rho_{t}^{K}\right) s_{K, t}^{u} f_{K, t} \frac{\chi_{K}}{\left(1-\chi_{K}\right)}\left(\mathbf{J}_{S E, t+1}-(1-\delta)\right) \\
+\left(1-\rho_{t}^{K}\right)\left(1-\rho_{t}^{O}\right)\left(1-\rho_{t}^{S}\right)\left(f_{S B, t}+f_{S E, t}\right) \frac{\chi_{S B}}{\left(1-\chi_{S B}\right)} \mathbf{J}_{O S B, t+1}
\end{array}\right\} .
\end{gathered}
$$

Now, based on as the job creation and capital supply conditions above when the policies are suppressed, we have

$$
\begin{gathered}
\frac{\chi_{L}}{\left(1-\chi_{L}\right)}\left(p_{L, t} \mathbb{F}_{n_{L, t}}\left(n_{L, t}, \omega_{t} k_{L, t}\right)-w_{L, t}+\frac{\psi_{L}}{q_{L, t}}\right)=w_{L, t}-b+\frac{\left(1-f_{L, t}\right) \chi_{L}}{\left(1-\chi_{L}\right)} \frac{\psi_{L}}{q_{L, t}} \\
-\frac{\chi_{K} s_{K, t}^{u} f_{K, t}}{\left(1-\chi_{K}\right)}\left(\frac{p_{L, t} z_{L, t} \mathbb{F}_{\omega k_{L}}\left(n_{L, t}, \omega_{t} k_{L, t}\right)+\left(1-\rho_{t}^{K}\right) q_{K, t}}{q_{K, t}}\right) \\
+\frac{\chi_{K} s_{K, t}^{u} f_{K, t}}{\left(1-\chi_{K}\right)} \mathbb{E}_{t} \Xi_{t+1 \mid t}\left(1-\rho_{t}^{K}\right)(1-\delta)-\frac{\chi_{S B}\left(f_{S B, t}+f_{S E, t}\right)}{\left(1-\chi_{S B}\right)} \frac{\psi_{S B}}{q_{S B, t}} .
\end{gathered}
$$

Rearranging terms, we have

$$
\begin{gathered}
w_{L, t}=\left(1-\chi_{L}\right) b+\chi_{L} \theta_{L, t} \psi_{L}+\frac{\left(1-\chi_{L}\right) s_{K, t}^{u} f_{K, t} \nu_{K}}{\left(1-\chi_{K}\right)}\left(\frac{p_{L, t} z_{L, t} \mathbb{F}_{\omega k_{L}}\left(n_{L, t}, \omega_{t} k_{L, t}\right)}{q_{K, t}}\right) \\
-\frac{\left(1-\chi_{L}\right) \chi_{K} s_{K, t}^{u} f_{K, t}}{\left(1-\chi_{K}\right)}\left(1-\rho_{t}^{K}\right)\left[1-\mathbb{E}_{t} \Xi_{t+1 \mid t}(1-\delta)\right] \\
+\frac{\left(1-\chi_{L}\right) \chi_{S B}\left(f_{S B, t}+f_{S E, t}\right)}{\left(1-\chi_{S B}\right)} \frac{\psi_{S B}}{q_{S B, t}},
\end{gathered}
$$

where we make use of fact that $f_{L, t} / q_{L, t}=\theta_{L, t}$. Finally, we can write

$$
\begin{aligned}
w_{L, t}= & \left(1-\chi_{L}\right) b+\chi_{L} \theta_{L, t} \tau_{t}^{v_{L}} \psi_{L} \\
& +\frac{\left(1-\chi_{L}\right) s_{K, t} f_{K, t} \chi_{K}}{\left(1-\chi_{K}\right)}\left(\frac{p_{L, t} z_{L, t} \mathbb{F}_{\omega k_{L}}\left(n_{L, t}, \omega_{t} k_{L, t}\right)}{q_{K, t}}\right) \\
& -\frac{\left(1-\chi_{L}\right) \chi_{K} s_{K, t} f_{K, t}}{\left(1-\chi_{K}\right)}\left(1-\rho_{t}^{K}\right)\left[1-\mathbb{E}_{t} \Xi_{t+1 \mid t}(1-\delta)\right] \\
& +\frac{\left(1-\chi_{L}\right) \chi_{S B}}{\left(1-\chi_{S B}\right)} \theta_{S B, t} \psi_{S B}+\frac{\left(1-\chi_{L}\right) \chi_{S B} f_{S E, t}}{\left(1-\chi_{S B}\right)} \frac{\psi_{S B}}{q_{S B, t}},
\end{aligned}
$$


where we make use of the fact that $f_{S B, t} / q_{S B, t}=\theta_{S B, t}$. Following similar steps by constructing $\left(\mathbf{W}_{S B, t}-\mathbf{W}_{U, t}\right)$, the wage for small-firm workers is

$$
\begin{gathered}
w_{S B, t}=\left(1-\chi_{S B}\right) b+\chi_{S B} \theta_{S B, t} \psi_{S B}+\nu_{S B} \frac{f_{S E, t} \psi_{S B}}{q_{S B, t}} \\
+\frac{\left(1-\chi_{S B}\right) \chi_{K} s_{K, t}^{u} f_{K, t}}{\left(1-\chi_{K}\right)}\left(\frac{p_{L, t} z_{L, t} \mathbb{F}_{\omega k_{L}}\left(n_{L, t}, \omega_{t} k_{L, t}\right)}{q_{K, t}}\right) \\
-\frac{\left(1-\chi_{S B}\right) \chi_{K} s_{K, t}^{u} f_{K, t}}{\left(1-\chi_{K}\right)}\left(1-\rho_{t}^{K}\right)\left[1-\mathbb{E}_{t} \Xi_{t+1 \mid t}(1-\delta)\right]+\frac{\left(1-\chi_{S B}\right) \chi_{L}}{\left(1-\chi_{L}\right)} \theta_{L, t} \psi_{L} .
\end{gathered}
$$

Note that both large-firm and small-firm wages depend on labor market tightness for large, small, and self-employed firms, as well as capital market tightness (recall that $f_{K, t}$, $q_{K, t}, f_{S E, t}$, and $q_{S B, t}$ are functions of their respective market tightness). Intuitively, higher labor market tightness (irrespective of the firm type) will put upward pressure on wages. This will also put downward pressure on capital rental rates as the outside options for both small firm owners and the self-employed are more attractive. Conversely, and similar to Finkelstein Shapiro (2014), higher capital market tightness will put downward pressure wages and upward pressure on capital rental rates. This is the case since higher capital market tightness - a lower probability of becoming self-employed - implies a less attractive self-employment outside option for salaried workers. By affecting market tightness, each of the cyclical subsidies will have an impact on wage dynamics and hence on labor demand.

\section{A.3 Calibration of Productivity Differentials Across Firm Types}

Busso, Fazio, and Levy (2012) use Mexican Census data to characterize the distribution of employment (as well as capital) based on firm size and the formality and legality status of the firm. Fernández and Meza (2014) use their evidence to determine the productivity gap between formal and informal firms focusing on legal firms alone since they consider that informal firms in their model are household firms that do not hire workers, i.e. household firms are self-employed firms (as defined in Busso, Fazio, and Levy (2012), legal firms are those that comply with mandated social security contributions for the all their salaried workers. Semi-legal firms have salaried workers but pay social security for only a fraction of them). We follow their approach (and notation) in calibrating the productivity parameters 
across firm types. In what follows, $L S F$ denotes legal semi-formal firms, $L F$ legal formal firms, $L I$ legal informal firms, $S L S F$ semi-legal semi-formal firms, and $I I$ illegal and informal firms (see Busso et al., 2012, for more details).

\section{A.3.1 Distribution of Employment by Employment Status and Definition of Firm Size in the Model}

Given the different types of firms in our model, our mapping between total factor productivity $(T F P)$ in the data and productivity in the model is more detailed as it considers both firm size and legal/formality status. We assume that the self-employed are those workers in firms of size [0-5] that are legal and informal. These represent self-employed (own-account) firms in the model. Workers in small firms are those working in firms of size [0-5] excluding informal and legal firms, as well as firms of sizes [6-10] and [11-50] excluding legal and formal firms. Large firms include workers that are formal and legal (regardless of firm size), as well as all workers in firms of size [+50]. We include all legal and formal firms within the same category - regardless of firm size - since their legality implies that policy makers can readily introduce cyclical wage subsidies by using firms' tax statements and social security records. This is not the case for firms that hire informal salaried workers since these workers are often not reported to the government.

Combining evidence on the share of self-employment for Mexico and the share of workers that are informal but legal (Busso, Fazio, and Levy, 2012), we assume that the self-employed account for 16 percent of the labor force, and small business owners 7 percent of the labor force. In turn, salaried workers in small and large firms account for 30 and 42 percent of the labor force, respectively.

\section{A.3.2 Productivity Differentials Based on Firm Size and Formality/Legality Status}

Based on the mapping between firms in the data and firm types in the model, we can use evidence on productivity differences by firm size to compute the steady-state sectoral productivity differentials in the model. Using Table 10 in Busso, Fazio, and Levy (2012) and 
following Fernández and Meza (2014), we have

$$
\begin{aligned}
\log \left(\frac{T F P_{L S F}}{T F P}\right)-\log \left(\frac{T F P_{L F}}{T F P}\right)=-0.959 & \Rightarrow \frac{T F P_{L S F}}{T F P_{L F}}=0.3833, \\
\log \left(\frac{T F P_{L I}}{T F P}\right)-\log \left(\frac{T F P_{L F}}{T F P}\right)=-1.759 & \Rightarrow \frac{T F P_{L I}}{T F P_{L F}}=0.1722, \\
\log \left(\frac{T F P_{S L S F}}{T F P}\right)-\log \left(\frac{T F P_{L F}}{T F P}\right)=-0.214 & \Rightarrow \frac{T F P_{S L S F}}{T F P_{L F}}=0.8073, \\
\log \left(\frac{T F P_{I I}}{T F P}\right)-\log \left(\frac{T F P_{L F}}{T F P}\right)=-0.881 & \Rightarrow \frac{T F P_{I I}}{T F P_{L F}}=0.4144,
\end{aligned}
$$

for firms of size [0-5],

$$
\begin{aligned}
\log \left(\frac{T F P_{L S F}}{T F P}\right)-\log \left(\frac{T F P_{L F}}{T F P}\right)=-0.910 & \Rightarrow \frac{T F P_{L S F}}{T F P_{L F}}=0.4025, \\
\log \left(\frac{T F P_{L I}}{T F P}\right)-\log \left(\frac{T F P_{L F}}{T F P}\right)=-0.688 & \Rightarrow \frac{T F P_{L I}}{T F P_{L F}}=0.5026, \\
\log \left(\frac{T F P_{S L S F}}{T F P}\right)-\log \left(\frac{T F P_{L F}}{T F P}\right)=-0.085 & \Rightarrow \frac{T F P_{S L S F}}{T F P_{L F}}=0.9185, \\
\log \left(\frac{T F P_{I I}}{T F P}\right)-\log \left(\frac{T F P_{L F}}{T F P}\right)=-0.632 & \Rightarrow \frac{T F P_{I I}}{T F P_{L F}}=0.5315,
\end{aligned}
$$

for firms of size [6-10], and

$$
\begin{aligned}
\log \left(\frac{T F P_{L S F}}{T F P}\right)-\log \left(\frac{T F P_{L F}}{T F P}\right)=-0.746 & \Rightarrow \frac{T F P_{L S F}}{T F P_{L F}}=0.4743, \\
\log \left(\frac{T F P_{L I}}{T F P}\right)-\log \left(\frac{T F P_{L F}}{T F P}\right)=-0.395 & \Rightarrow \frac{T F P_{L I}}{T F P_{L F}}=0.6737, \\
\log \left(\frac{T F P_{S L S F}}{T F P}\right)-\log \left(\frac{T F P_{L F}}{T F P}\right)=-0.092 & \Rightarrow \frac{T F P_{S L S F}}{T F P_{L F}}=0.9121, \\
\log \left(\frac{T F P_{I I}}{T F P}\right)-\log \left(\frac{T F P_{L F}}{T F P}\right)=-0.701 & \Rightarrow \frac{T F P_{I I}}{T F P_{L F}}=0.4961,
\end{aligned}
$$


for firms of size [11-50]. Finally, for firms of size [+50], we have

$$
\begin{aligned}
\log \left(\frac{T F P_{L S F}}{T F P}\right)-\log \left(\frac{T F P_{L F}}{T F P}\right)=-0.574 & \Rightarrow \frac{T F P_{L S F}}{T F P_{L F}}=0.5633, \\
\log \left(\frac{T F P_{L I}}{T F P}\right)-\log \left(\frac{T F P_{L F}}{T F P}\right)=-0.491 & \Rightarrow \frac{T F P_{L I}}{T F P_{L F}}=0.6120, \\
\log \left(\frac{T F P_{S L S F}}{T F P}\right)-\log \left(\frac{T F P_{L F}}{T F P}\right)=-0.159 & \Rightarrow \frac{T F P_{S L S F}}{T F P_{L F}}=0.8530, \\
\log \left(\frac{T F P_{I I}}{T F P}\right)-\log \left(\frac{T F P_{L F}}{T F P}\right)=-1.039 & \Rightarrow \frac{T F P_{I I}}{T F P_{L F}}=0.3538
\end{aligned}
$$

Using Tables 6 and 10 in Busso, Fazio, and Levy (2012), we can construct employmentweighted measures of TFP for each type of firm (self-employed, $T F P_{S E}$, small, $T F P_{S B}$, and large, $\left.T F P_{L}\right)$. Then, $T F P$ in self-employment is

$$
T F P_{S E}=T F P_{[0-5], L I}
$$

TFP in small firms is computed as:

$$
\begin{gathered}
\operatorname{TFP}_{S B}=\left(\frac{0.79}{32.17}\right) T F P_{[0-5], L S F}+\left(\frac{1.69}{32.17}\right) T F P_{[0-5], S L S F}+\left(\frac{10.94}{32.17}\right) T F P_{[0-5], I I} \\
+\left(\frac{1.63}{32.17}\right) T F P_{[6-10], L I}+\left(\frac{0.50}{32.17}\right) T F P_{[6-10], L S F}+\left(\frac{1.92}{32.17}\right) T F P_{[6-10], S L S F} \\
+\left(\frac{3.66}{32.17}\right) T F P_{[6-10], I I}+\left(\frac{2.39}{32.17}\right) T F P_{[11-50], L I}+\left(\frac{0.57}{32.17}\right) T F P_{[11-50], L S F} \\
+\left(\frac{4.72}{32.17}\right) T F P_{[11-50], S L S F}+\left(\frac{3.36}{32.17}\right) T F P_{[11-50], I I},
\end{gathered}
$$

and TFP in large firms is computed as: 


$$
\begin{gathered}
T F P_{L}=\left(\frac{0.77}{44.02}\right) T F P_{[0-5], L F}+\left(\frac{1.09}{44.02}\right) T F P_{[6-10], L F}+\left(\frac{3.84}{44.02}\right) T F P_{[11-50], L F} \\
+\left(\frac{14.67}{44.02}\right) T F P_{[+50], L F}+\left(\frac{7.74}{44.02}\right) T F P_{[+50], L I}+\left(\frac{1.19}{44.02}\right) T F P_{[+50], L S F} \\
+\left(\frac{13.75}{44.02}\right) T F P_{[+50], S L S F}+\left(\frac{1.18}{44.02}\right) T F P_{[+50], I I} .
\end{gathered}
$$

Using the values for $T F P$ relative to $T F P_{L F}$ by firm size and legality/formality status above, we have

$$
\begin{gathered}
\text { TFP } P_{S E}=0.1722 \\
T F P_{S B}=\left(\frac{0.79}{30.54}\right)(0.3833)+\left(\frac{1.69}{30.54}\right)(0.8073)+\left(\frac{10.94}{30.54}\right)(0.414)\left(\frac{1.92}{30.54}\right)(0.9185) \\
+\left(\frac{1.63}{32.17}\right)(0.5026)+\left(\frac{0.50}{30.54}\right)(0.4025)+\left(\frac{2.39}{30.54}\right)(0.6737)+\left(\frac{0.57}{30.54}\right)(0.4743) \\
+\left(\frac{3.66}{30.54}\right)(0.5315)+\left(\frac{4.72}{30.54}\right)(0.9121)+\left(\frac{3.36}{30.54}\right)(0.4961) \\
+\left(\frac{14.67}{44.02}\right)(1)+\left(\frac{7.74}{44.02}\right)(0.6737)+\left(\frac{1.19}{44.02}\right)(0.4743) \\
+\left(\frac{13.75}{44.02}\right)(0.9121)+\left(\frac{1.18}{44.02}\right)(0.4161) \\
+\left(\frac{0.77}{44.02}\right)(1)+\left(\frac{1.09}{44.02}\right)(1)+\left(\frac{3.84}{44.02}\right)(1)
\end{gathered}
$$

This yields $T F P_{S E}=0.1722, T F P_{S B}=0.6150$, and $T F P_{L}=0.8901$. Then, normalizing $T F P_{S E}$ to 1 , and using the mapping $T F P_{L}=z_{L}, T F P_{S B}=z_{S B}$, and $T F P_{S E}=z_{S E}$ between the data and the model, we have

$$
z_{L}=5.1690, \quad z_{S B}=3.5714, \quad z_{S E}=1
$$




\section{A.4 Robustness and Additional Experiments}

\section{A.4.1 Asymmetry in Elasticities of Substitution between Types of Output}

Assuming that $\phi_{a}=0.8$ and $\phi_{s}=0.6$ makes the main conclusions under the benchmark calibration starker. The main differences are as follows. With hiring subsidies for self-employed firms (i.e., small firm creation subsidies), consumption decreases by more (as capital search expenditures are more responsive) and there is no difference in the recovery speed of total output relative to the benchmark economy. A similar result obtains regarding the expansion of intermediation services for small firms, where consumption falls by more and the output recovery is more sluggish relative to the results in the main text. Similarly, with hiring subsidies for existing small firms, the gains in terms of a faster initial recovery in consumption, and output are more short-lived relative to the benchmark results. Finally, the gains from hiring subsidies for large firms and the improvement in matching for employment in large firms are larger. Thus, the main conclusions do not change. Conversely, assuming that $\phi_{a}=0.6$ and $\phi_{s}=0.8$ entails the following changes. Introducing hiring subsidies for self-employed firms make consumption less volatile and makes output recover faster. Thus, under this alternative calibration, the gains from these subsidies are somewhat larger relative to the benchmark calibration under the same policy. With hiring subsidies for small firms, the initial faster recovery in total output is longer (even though it still fades away in the medium term). Despite these changes, the main message of the paper does not change. Similarly, the recovery of output under better matching for employment in small firms is less sluggish, but the same policy for large firms still dominates. Importantly, regardless of

the calibration of $\phi_{a}$ and $\phi_{s}$, the adverse aggregate impact of introducing self-employment search (startup) subsidies does not change.

\section{A.4.2 Higher Volatility of Self-Employment Separation Probabilities}

Calibrating the model to capture the relative volatility of self-employment separation probabilities (as opposed to the relative volatility of salaried separation probabilities as in the benchmark model) in the data does not change the main conclusions. 


\section{A.4.3 Financing Cyclical Subsidies Through Government Debt}

We follow Campolmi, Faia, and Winkler (2011) and allow for subsidies to firms to be financed partly through government debt. If the government uses lump-sum taxes and government debt to finance expenditures, the government budget constraint is

$$
\begin{aligned}
& T_{t}+b_{t}^{*}=b u_{t}+\left(1-\tau_{t}^{v_{L}}\right) \psi_{L} v_{L, t}+\left(1-\tau_{t}^{v_{S E}}\right) \psi_{S E} v_{S E, t} n_{S E, t}+\left(1-\tau_{t}^{v_{S B}}\right) \psi_{S B} v_{S B, t} o_{S B, t} \\
&+\left(1-\tau_{t}^{\kappa}\right) \kappa\left(s_{K, t}\right)+R_{t-1} b_{t-1}^{*}+g_{t}+\left(1-\tau_{t}^{w_{L}}\right) w_{L, t} n_{L, t}+\left(1-\tau_{t}^{w_{S B}}\right) w_{S B, t} n_{S B, t} \\
&+\left(\tau_{t}^{m_{L}}-1\right) m_{L}\left(v_{L,}, u_{t}\right)+\left(\tau_{t}^{m_{S B}}-1\right) m_{S B}\left(v_{S B, t} o_{S B, t}, u_{t}\right) .
\end{aligned}
$$

where $g_{t}$ is government spending. Following Totzek and Winkler (2010) and Campolmi, Faia and Winkler (2011), we assume that a fraction $\gamma_{b}$ of government expenditures is financed through debt, so that

$$
b_{t}^{*}=\gamma_{b}\left(\begin{array}{c}
b u_{t}+\left(1-\tau_{t}^{v_{L}}\right) \psi_{L} v_{L, t}+\left(1-\tau_{t}^{\kappa}\right) \kappa\left(s_{K, t}\right)+R_{t-1} b_{t-1}^{*}+g_{t}-T_{t} \\
+\left(1-\tau_{t}^{v_{S E}}\right) \psi_{S E} v_{S E, t} n_{S E, t}+\left(1-\tau_{t}^{v_{S B}}\right) \psi_{S B} v_{S B, t} o_{S B, t} \\
+\left(1-\tau_{t}^{w_{L}}\right) w_{L, t} n_{L, t}+\left(1-\tau_{t}^{w_{S B}}\right) w_{S B, t} n_{S B, t} \\
+\left(\tau_{t}^{m_{L}}-1\right) m_{L}\left(v_{L,}, u_{t}\right)+\left(\tau_{t}^{m_{S B}}-1\right) m_{S B}\left(v_{S B, t} o_{S B, t}, u_{t}\right)
\end{array}\right) .
$$

The impact of the policies is qualitatively similar to the one where the cyclical subsidies are fully financed using lump-sum taxation.

\section{A.4.4 Financing Hiring Subsidies for Small Firms with Payroll Taxes on Large Firms}

While it may be feasible to introduce a hiring subsidy to small firms during a downturn, raising the revenue for that subsidy through distortionary taxes on small firms may be more difficult given the high rates of informality among these firms. Assuming that the hiring subsidy for small firms is financed through an increase in payroll taxes for large firms naturally reduces the beneficial impact from the subsidy relative to the case with lumpsum taxation or government debt. In particular, relative to the no-policy case, the recovery of consumption, investment, and output become more sluggish in the medium term, but 
unemployment still falls due to a surge in small-firm employment.

\section{A.4.5 Policies with Identical Subsidy Rates}

The benchmark model assumed the same fiscal cost when analyzing each of the policies and allowed the cyclical subsidies to adjust endogenously. This generated different subsidy rates depending on the type of policy. If we assume the same (impact) subsidy rate for all policies and let the fiscal cost adjust endogenously, the results can change in important ways for some of the policies. If we assume a subsidy rate of 5 percent on impact for all policies (see Banerji et al., 2014), hiring subsidies for small and self-employed firms have a negligible impact on consumption and output dynamics, though they still limit the initial rise in unemployment after the shock (in contrast to the benchmark results, a hiring subsidy for existing small firms only limits the rise in unemployment and does not lead to a drastic reduction in unemployment after the shock). This result occurs because the hiring subsidies need to be substantially higher to have a quantitative impact. In contrast, the effect of hiring subsidies for large firms is quantitatively similar to the main results, largely because the subsidy rate in the latter is not much higher than 5 percent. For similar reasons the results for improved matching for employment in either large or small firms do not change much either. Conversely, a subsidy of 5 percent implies that wage subsidies do have a larger quantitative impact (even though the fiscal cost also increases substantially), but the qualitative results do not change.

\section{A.4.6 Combining Individual Policies}

As should be the case, combining hiring subsidies with self-employment startup subsidies offsets the benefits from the hiring subsidies, so that the policy mix is much less effective in aiding the recovery of total output and reducing aggregate volatility, even though it does limit the rise in unemployment. Similarly, combining the self-employment startup subsidies with improvements in job intermediation (i.e., matching) implies that the gains obtained when intermediation is focused on large firms are smaller. 


\section{A.4.7 Exogenous Separation Probabilities}

The same policy experiments in a model with exogenous separation probabilities yield qualitatively similar results for the fiscal output and employment multipliers. Also, without the endogenous response in separations, all policies either limit the rise in unemployment or reduce unemployment by more relative to the benchmark model. The results for all other variables under exogenous separations remain qualitatively similar to those in the benchmark impulse response functions.

\section{A.5 Additional Details on Main Results}

Figures A1 through A5 present complementary impulse responses to those shown in the main text. Along the figures' columns a particular policy is in place, and the figures' rows show a particular variable's response. Using these figures, in what follows we present greater details on the dynamic adjustments driving the results shown in the figures in the main text. The impact of different policies is always compared to the no-policy case. Moreover, the discussion makes use of the explicit wage statements in equations (A1) and (A2). In what follows, and given the input credit relationship between large firms and the self-employed in the model, when we refer to an increase (decrease) in the supply of capital to the selfemployment sector, we are implicitly referring to a fall (rise) in capital usage among large firms (even though the capital stock is also adjusting).

Hiring Subsidy for Large Firms. (First column of Figures A1 through A5). This policy generates a rise in large-firm vacancy postings, which puts upward pressure on largefirm labor market tightness and limits the contraction in capital usage, which results in a smaller contraction in investment and also puts upward pressure on large- and small-firm wages, with the latter recovering earlier and the former initially falling by less. The fall in consumption is now limited by upward pressure on wages, the fall in expenditures on capital search, and the expansion in large-firm salaried employment (the contraction in selfemployment earnings is also subdued). The behavior of salaried employment and the decision to allocate relatively more capital within large firms aids the recovery in large-firm output, and in turn, total output. The expansion in large-firm employment counteracts the larger 
contraction in small-firm employment and self-employment, which explains unemployment rising by less and returning back to steady state faster. These results are consistent with the positive effects of hiring subsidies documented in Campolmi, Faia, and Winkler (2011) and Faia, Lechthaler, and Merkl (2013) in a different context, mainly in models with a single firm and employment type.

Hiring Subsidy for Existing Small Firms. (First column of Figures A1 through A5). Higher vacancy postings by existing small firms puts upward pressure on small-firm salaried labor market tightness and leads to a reduction in both large-firm market tightness (which induces a larger initial fall in wages) and capital market tightness. The reduction in expenditures on capital search and the sharp expansion in small-firm salaried employment initially reduce the size of the contraction in consumption. The fall in large-firm vacancies reduces large-firm capital usage and increases capital supply to the self-employed in the period of the shock, ultimately resulting in a smaller initial fall in investment. Higher small firm vacancy posting puts upward pressure on large-firm wages, leading to a more sluggish recovery in large-firm vacancies and to a medium term slower recovery in investment. The sharp rise in small-firm employment aids the rebound in small-firm output, in turn aiding the recovery in total output (although only initially), and is large enough to offset the fall in both large-firm employment and self-employment (so unemployment in fact decreases). Note that the large response of small-firm salaried employment is mainly due to the fact that the subsidy rate is much larger compared to the hiring subsidy rate for larger firms. This is partly explained by the fact that we are assuming a fiscal package of the same size (0.2 percent of output), but the cost of posting vacancies for small firms is slightly lower than the cost for large firms. Furthermore, the subsidy rate adjusts to the size of the fiscal package. If we were to assume the same subsidy rate for all policies (and let the cost of the fiscal package adjust endogenously), unemployment would rise by less, but remain fairly persistent as the recovery takes hold.

\section{Cyclical Improvements in Job Intermediation (Matching Efficiency) for Em-} ployment in Large Firms. (Second column of Figures A1 through A5). Results are analogous to hiring subsidies for large firms. The expected cost of posting vacancies for large firms decreases (mainly due to an increase in the job-filling rate instead of a fall in 
the cost per vacancy as was the case with the hiring subsidy), bolstering vacancies in the period of the shock and increasing capital usage among large firms. This leads to a smaller fall in investment and in turn aids the recovery in total output. The reduction in capital search expenditures by households implies that consumption contracts by less. The behavior of large-firm vacancies affects labor market tightness and implies that the policy provides partial income protection by preventing wages across all firm types from falling as much. Finally, the policy induces an expansion in employment among large firms that more than offsets the fall in employment among small firms and ultimately generates a reduction in unemployment. While the qualitative impact of the policy is similar to the hiring subsidy, the quantitative effects are larger.

\section{Cyclical Improvements in Job Intermediation (Matching Efficiency) for Em-} ployment in Small Firms. (Second column of Figures A1 through A5). There is a subdued effect on aggregate dynamics, and a similar effect to hiring subsidies for existing small firms. Interestingly, this job intermediation policy is less effective in reducing unemployment in the aftermath of the shock for this group of firms relative to a similar policy for large firms (despite the importance of small firms for aggregate employment). One key difference relative to hiring subsidies is that capital supply to the self-employed (capital usage in large firms) rises (falls) my more, which explains the behavior of investment. Moreover, since the downward adjustment in small firm wages is less stark, the recovery in small firm output is weaker, which in turn explains the short-term positive effects on unemployment.

Hiring Subsidy for Self Employed Individuals. (Third column of Figures A1 through A5). Small firm owners expand, generating a larger reallocation of capital from the large-firm sector into the self-employment sector (the increase in vacancy postings by the self-employed puts upward pressure on large-firm wages via labor market tightness, reducing the incentive of large firms to hire workers and hence in-house capital usage). Capital supply to the self-employed surges, and the Nash rental rate for self-employed workers (not shown) falls by more so that self-employment earnings contract by less. Wages for both small and large-firm workers are less volatile, but consumption initially falls by slightly more given higher capital-search expenditures. Vacancy postings by existing small firms and the selfemployed bounce back after the shock putting upward pressure on wages via higher market 
tightness. The rise in capital search expenditures is short-lived, and expenditures begin their return back to steady state faster, which explains why consumption does not fall by more after the shock. As capital usage among large firms initially contracts by more, investment exhibits a sharper contraction as well. The rise in both small-firm salaried employment and the measure of small business owners leads to a sharp recovery in small-firm output, aiding the recovery in total output despite the more persistent contraction in large-firm output. The behavior of employment outside the large firm sector is responsible for limiting the rise in unemployment. However, unemployment remains persistently above steady-state due partly to the persistent fall in both large-firm employment and self-employment, where the latter is explained by the outflow from of self-employment and into small business owner status.

Subsidy for the Creation of Self-Employed Firms. (Third column of Figures A1 through A5). The demand for capital supplied by large firms rises and a reallocation of capital towards the self-employment sector takes place. The surge in capital demand from potential self-employed individuals reduces capital usage among large firms by more, leading to a larger contraction in large-firm vacancies and employment, large-firm output, and investment. A similar but milder effect is observed for small-firm salaried employment (small firms are not directly impacted by capital reallocation, but they are affected by the change in the self-employment outside option); if each small firm were using more than one unit of matched capital, the reallocation process would likely have a larger impact on salaried employment among large and small firms. Thus, our results can be seen as a lower bound for the response of small-firm salaried employment. Salaried labor market tightness across firm types contracts and puts downward pressure on wages, but it becomes easier to move into self-employment, which puts upward pressure on wages. Ultimately wages do not adjust much relative to the benchmark economy, but salaried employment contracts by more, which along with the sharp rise in expenditures on capital search explains the larger contraction in consumption. The rise in self-employment is large enough to generate a smaller increase in unemployment (this merely slows down the rise in unemployment, and the policy has no discernible impact on unemployment dynamics in the medium term). Finally, note that, while the contraction in small-firm output worsens only slightly, the more sluggish recovery in large-firm output explains the slower recovery in total output. Since it may be difficult 
to raise revenue for this policy by increasing the cost of hiring during an expansion, we can alternatively assume that this subsidy is financed via a temporary increase in payroll taxes for large firms. This enhances the adverse quantitative effects of the policy by generating an even larger contraction in large-firm employment and output.

Wage Subsidy for Large Firms. (Fourth column of Figures A1 through A5). The reduction in large-firm capital usage is subdued, which implies that salaried vacancies among large firms fall by less, generating a smaller contraction in investment and employment among large firms and a faster recovery in investment. In turn, large-firm output recovers at a faster rate. The supply of capital to the self-employed is smaller, so self-employment initially expands by less. The smaller decrease in large-firm vacancies implies that large-firm labor market tightness falls by less, putting upward pressure on wages among all firm types. Since the adjustment in wages is smaller, both small firms and the self-employed cut vacancies by more, generating a larger contraction in small-firm salaried employment in subsequent periods and small-firm output exhibits a more sluggish recovery. The smaller fall in largefirm employment and wages, combined with the fall in household resources spent on capital search, leads to a smaller fall in aggregate consumption. Importantly, the contraction in small-firm salaried employment more than offsets the smaller fall in large-firm employment, which leads to a sharper increase in unemployment.

Wage Subsidy for Small Firms. (Fourth column of Figures A1 through A5). The value of having salaried workers in small firms rises and limits the fall in vacancy postings among small and self-employed firms, putting upward pressure on labor market tightness and wages in both salaried firm types and pushing larger firms to reduce vacancy postings by more. Surprisingly, capital usage exhibits a similar fall to the one observed under the wage subsidies for large firms (despite having a larger fall in large-firm vacancies), which also implies a smaller fall in investment (existing small firms already have a capital relationship and the behavior of labor market tightness puts downward pressure on the Nash rental rates, which decreases the incentive to supply capital to the self-employed). Despite the larger contraction in salaried employment among large firms in the aftermath of the shock, the rise in small-firm salaried employment and wages for both firm types, along with the initial reduction in the resources devoted to capital search (not shown), leads to a marginally 
smaller fall in consumption. Even though small-firm output recovers faster, the fall in largefirm output implies that the policy has a negligible effect on the recovery path of total output. Finally, given the large expansion in small-firm salaried employment, the rise of unemployment after the shock is smaller.
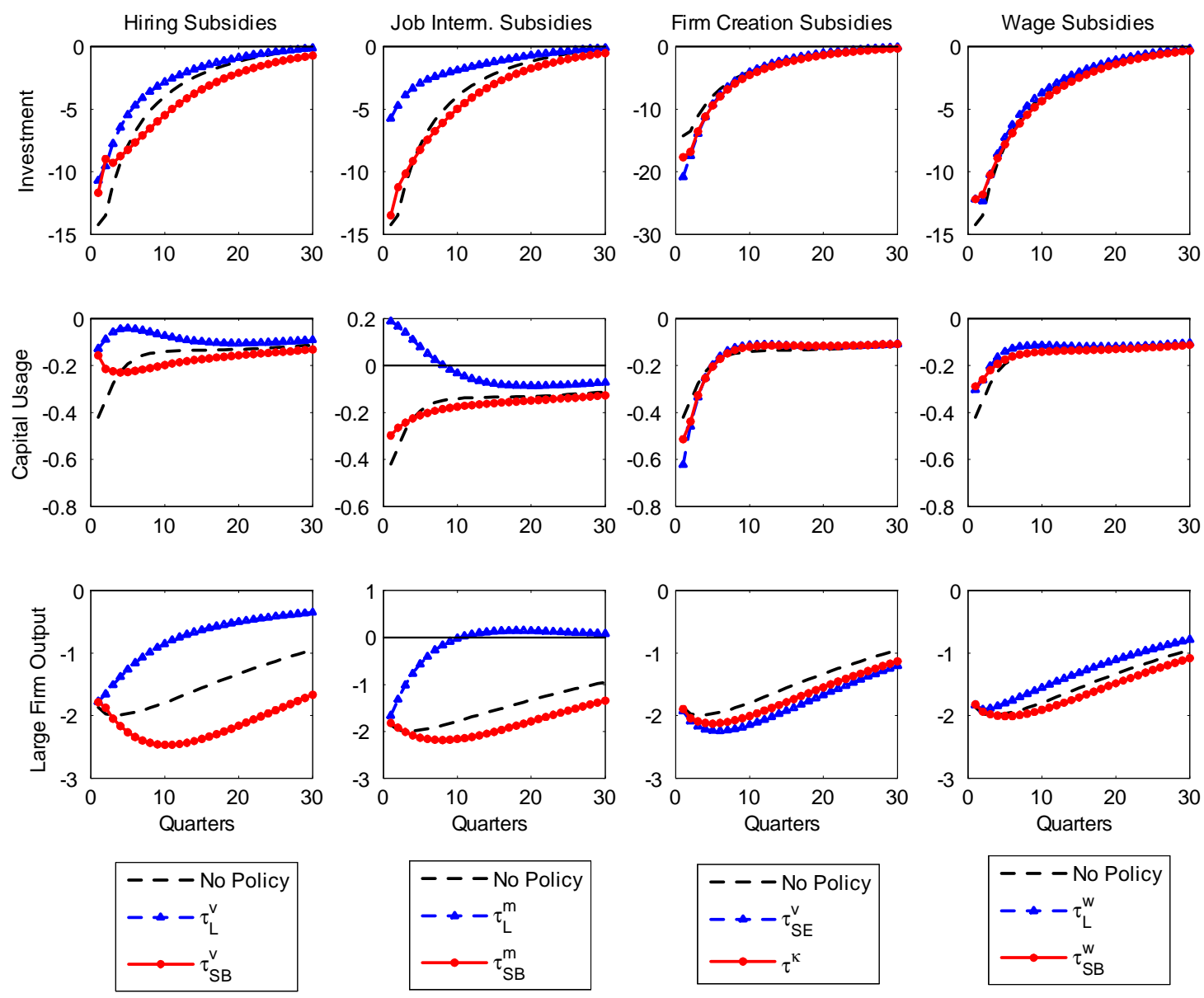

Figure A1

Response to a 1 percent negative productivity shock (quarters after shock): Investment, capital usage by large firms, and large firm output. 

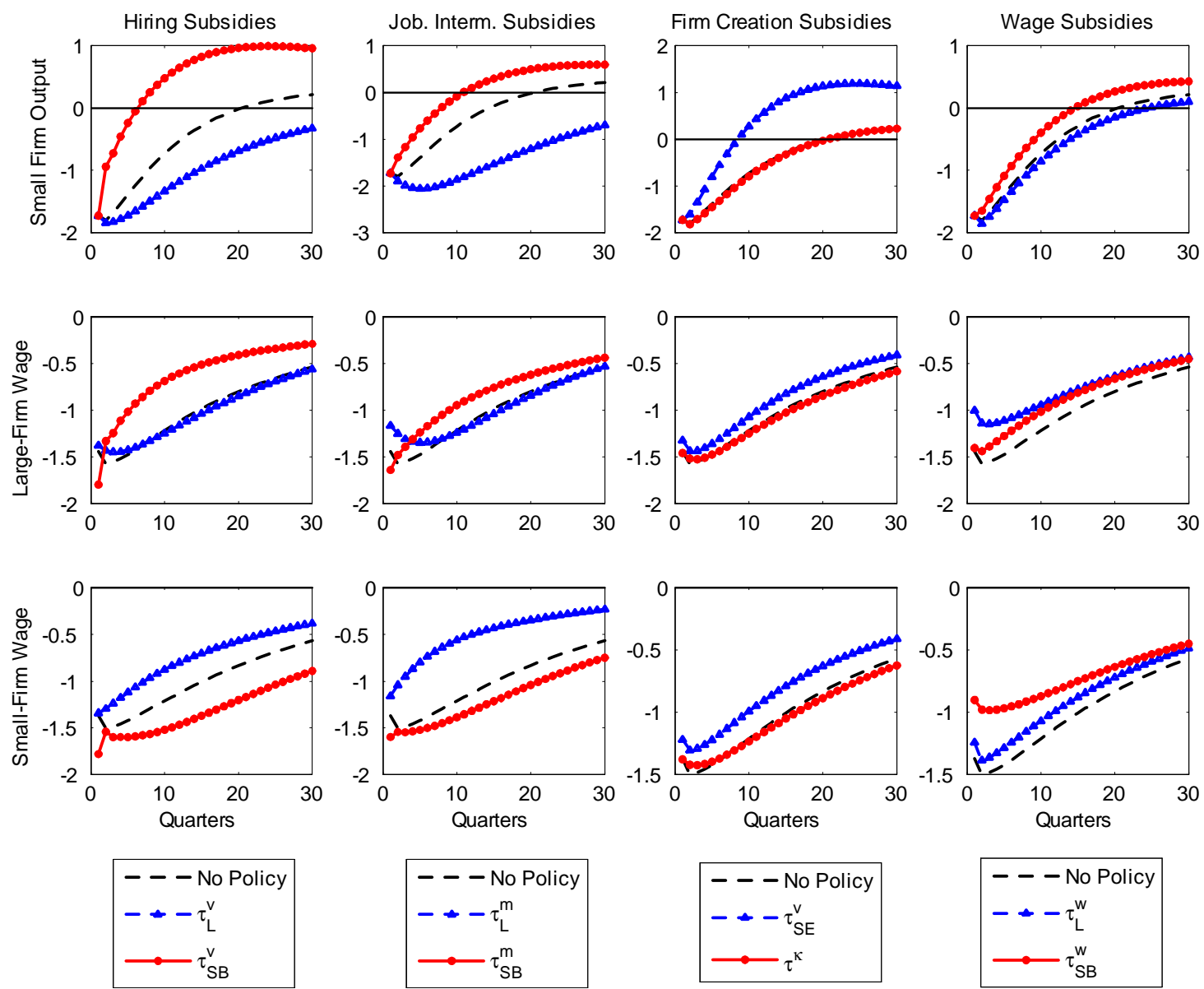

Figure A2

Response to a 1 percent negative productivity shock (quarters after shock):

Small firm output, large firm wage, and small firm wage. 

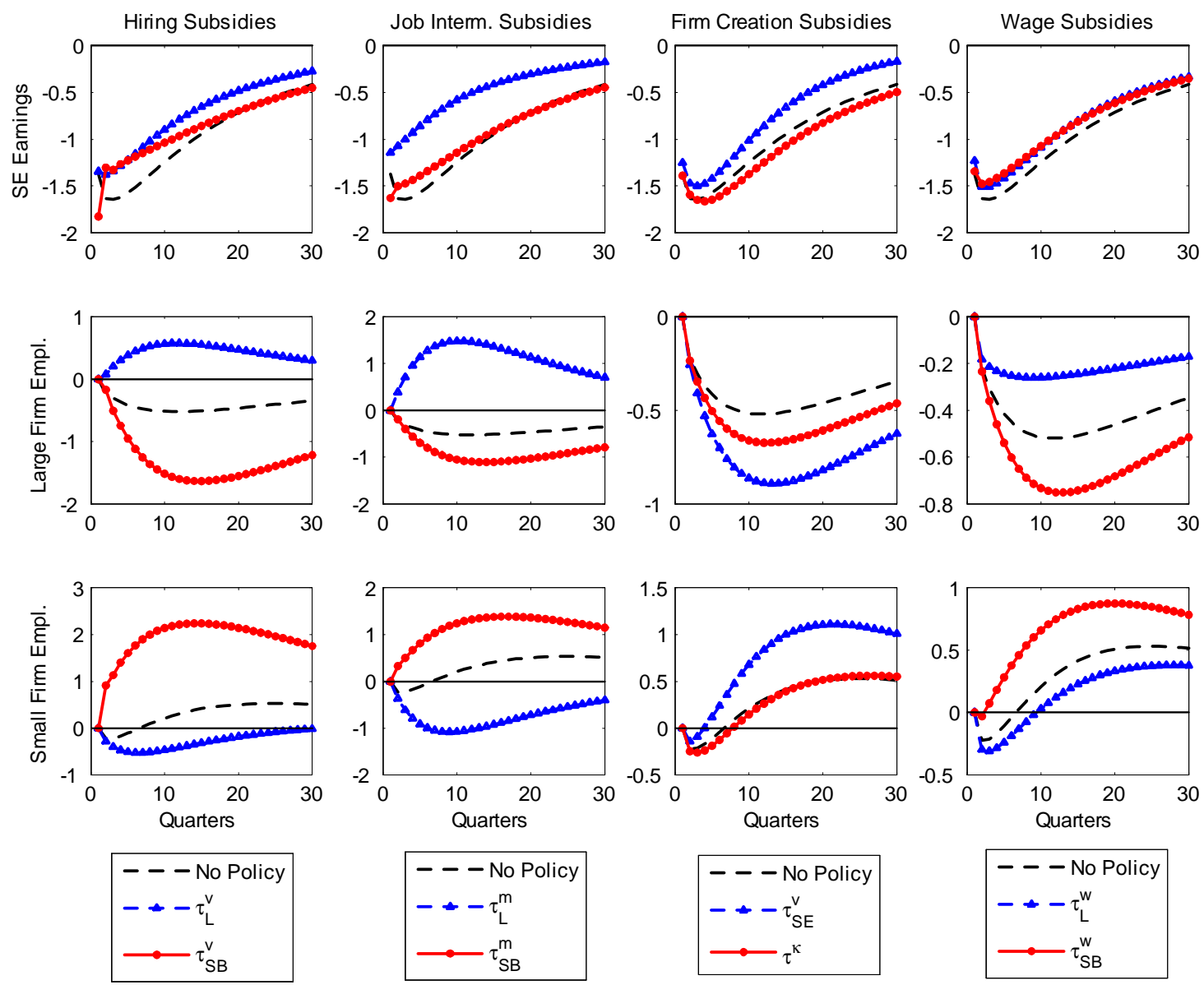

Figure A3

Response to a 1 percent negative productivity shock (quarters after shock): Self employed earnings, large firm employment, and small firm employment. 

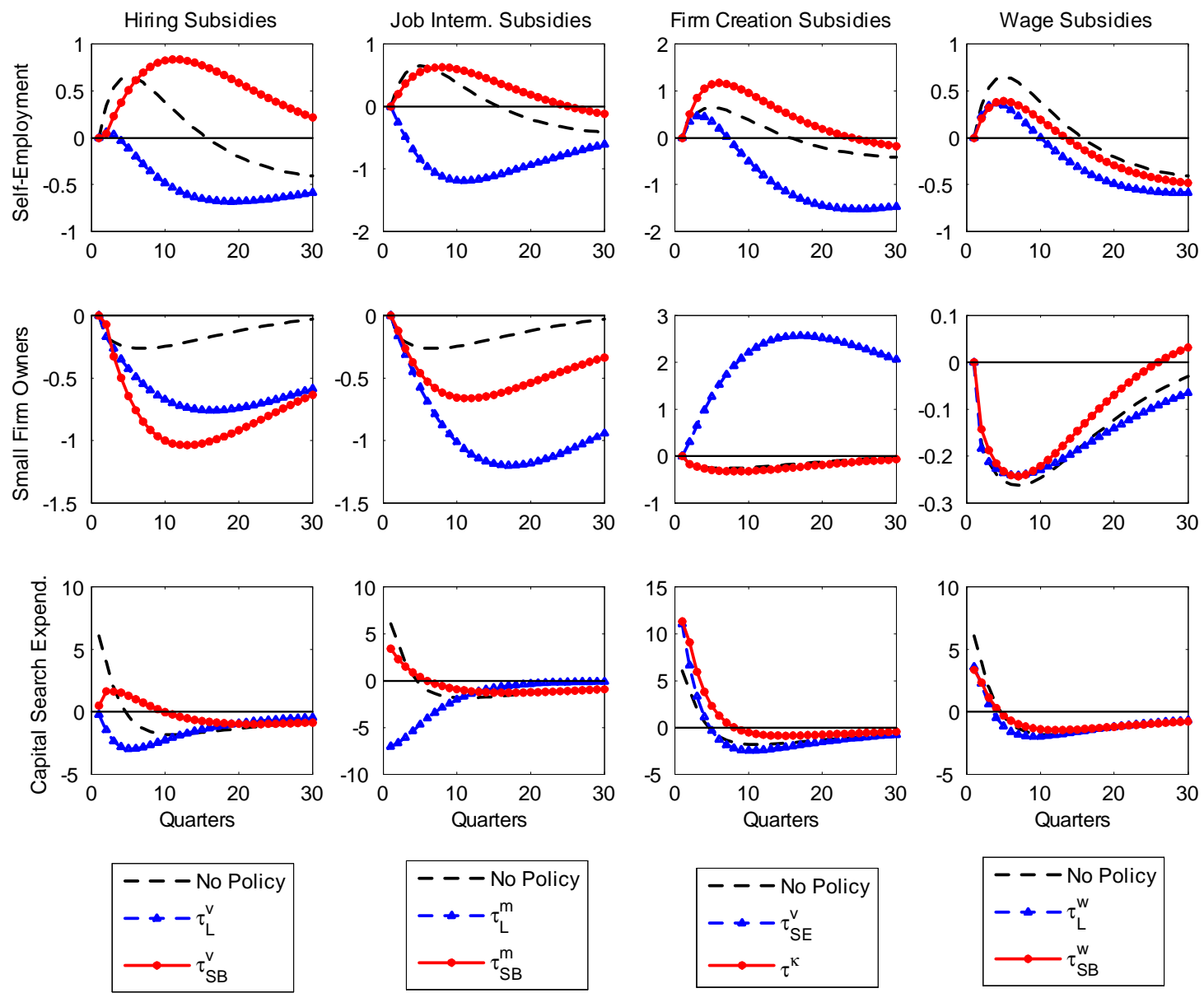

Figure A4

Response to a 1 percent negative productivity shock (quarters after shock): Self employment, small firm owners, and capital search expenditures. 

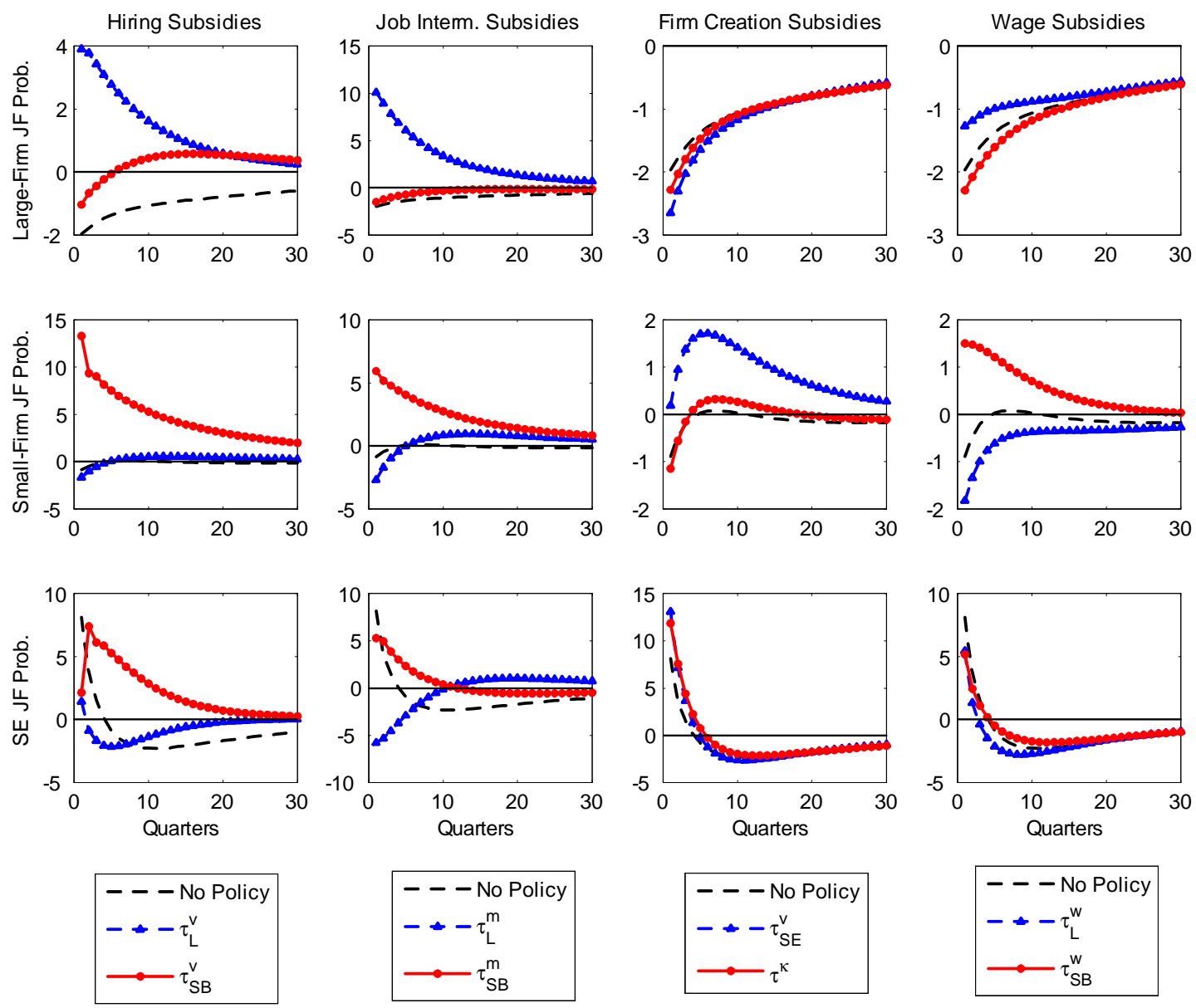

Figure A5

Response to a 1 percent negative productivity shock (quarters after shock): Job-filling probabilities of large firms, small firms, and self-employed (micro) firms. 